\title{
The rheological transition in plagioclase-bearing magmas
}

\author{
D. Picard, ${ }^{1,2,3,4}$ L. Arbaret, ${ }^{1,2,3}$ M. Pichavant, ${ }^{1,2,3}$ R. Champallier, ${ }^{1,2,3}$ and P. Launeau ${ }^{5}$
}

Received 18 July 2012; revised 5 December 2012; accepted 14 January 2013; published 16 April 2013.

[1] Volcanological processes, such as melt segregation, ascent, and eruption, are directly dependent on the rheological behavior of magmatic suspensions. An increase of the crystal fraction of the suspension leads to the formation of a solid-particle network, which abruptly increases magma viscosity. The crystal fraction at which this rheological transition occurs depends on parameters such as the strain rate and the size, shape, and sorting of particles. To determine the influence of the crystal shape on the rheological transition, suspensions of plagioclase, a representative anisometric crystal, have been investigated at high temperatures and pressures. Synthetic suspensions with crystal fractions $\left(\phi_{\mathrm{s}}\right)$ ranging from 0.38 to 0.75 were deformed both in compression and torsion in a Paterson apparatus at 300 $\mathrm{MPa}, 900^{\circ} \mathrm{C}$ and $800^{\circ} \mathrm{C}$, and for strain rates between $1.0 \times 10^{-5}$ and $1.0 \times 10^{-3} \mathrm{~s}^{-1}$. All suspensions exhibit a non-Newtonian shear thinning rheological behavior.

The experimental results, coupled with existing data and models at low crystal fractions $\left(\phi_{\mathrm{s}}<0.3\right)$, allow several rheological domains to be identified, from steadystate flow to strain weakening, each characterized by a specific microstructure. In particular, a progressive evolution from a pervasive to a strain partitioning fabric is found when increasing the crystal fraction. Our results highlight the influence of both the strain rate and the shape of crystals on the rheological behavior of magmas. During crystallization, magmatic suspensions of anisometric minerals such as plagioclase would develop a solid-particle network earlier $\left(\phi_{\mathrm{s}} \sim 0.3\right)$ than suspensions of isometric minerals $\left(\phi_{\mathrm{s}} \sim 0.5\right)$. Our study shows that localization of strain early in the crystallization history of mushy zones in the magma chamber, near the conduit margins, and at the base of lava flows would facilitate the mobilization, the transfer, and the final emplacement at the surface of highly viscous, feldspar-rich magmas.

Citation: Picard, D., L. Arbaret, M. Pichavant, R. Champallier, and P. Launeau (2013), The rheological transition in plagioclase-bearing magmas, J. Geophys. Res. Solid Earth, 118, 1363-1377, doi:10.1002/jgrb.50091.

\section{Introduction}

[2] Melt segregation from source rocks, magma ascent toward the surface, eruption or shallow-level emplacement, and crystallization of magma are all directly governed by the rheological behavior of magmatic suspensions [Petford, 2003]. Magma rheology is a complex function of the relative proportions of melt, gas bubbles, and crystals in the suspension [Bagdassarov et al., 1994]. Silicate melts behave as Newtonian fluids at low strain rates [Dingwell et al., 1996; Richet et al., 1996, 2006; Giordano et al., 2008], viscosity being mainly dependent on the chemical composition of

\footnotetext{
${ }^{1}$ Université d'Orléans, Orléans, France.

${ }^{2} \mathrm{CNRS} /$ Institut National des Sciences de 1'Univers, Orléans, France.

${ }^{3}$ Bureau de Recherches Géologiques et Minières, Orléans, France.

${ }^{4}$ Now at Laboratoire de Mécanique des Solides, Ecole Polytechnique, Palaiseau Cedex, France.

${ }^{5}$ Laboratoire de Planétologie et Géodynamique, Université de Nantes, Nantes, France.

Corresponding author: D. Picard, Laboratoire de Mécanique des Solides, Ecole Polytechnique, 91128 Palaiseau Cedex, France. (picard@Ims.polytechnique.fr)

(C)2013. American Geophysical Union. All Rights Reserved. 2169-9313/13/10.1002/jgrb.50091
}

the melt (expressed for example by its NBO/T) [Bottinga and Richet, 1995; Mysen, 1990], water content [Hess and Dingwell, 1996; Richet et al., 1996], and temperature [Hess et al., 1996]. A tendency to a shear thinning behavior has been evidenced at high strain rates [Shaw, 1969; Ryerson et al., 1988]. The influence of bubbles is determined by the capillary number $(\mathrm{Ca}$, balance between viscous and surface tension forces) and on their proportion [Bagdassarov and Dingwell, 1992; Stein and Spera, 1992; Manga et al., 1998; Lejeune et al., 1999; Bagdassarov and Pinkerton, 2004]. For Ca numbers $>0.5$, bubbles deform and the viscosity of the suspension decreases compared with the pure melt [Bagdassarov and Dingwell, 1992]. For $\mathrm{Ca}<0.5$, bubbles remain spherical and serve to increase the viscosity compared with pure melt [Manga et al., 1998]. The crystal fraction is known to have a major influence on the rheological behavior of magmatic suspensions. The behavior of suspensions made of nearly isometric particles is relatively well known. Their mechanical behavior at low crystal fractions can be modeled using the Einstein-Roscoe equation [Einstein, 1911; Roscoe, 1952, Ryerson et al., 1988; Pinkerton and Stevenson, 1992; Lejeune and Richet, 1995; Caricchi et al., 2007; Champallier et al., 2008; Cordonnier et al., 2009]. On increasing the crystal fraction, the 
rheology of the suspensions evolves from a Newtonian to a non-Newtonian flow behavior [Caricchi et al., 2007; Champallier et al., 2008; Cordonnier et al., 2009] as an interconnected crystal framework capable of transmitting deviatoric stresses develops [Saar et al., 2001; Petford, $2003]$. The critical crystal fraction $\phi_{c}$ at which this transition occurs depends on several parameters such as the strain rate, size, size distribution, and shape of particles [Arzi, 1978; Van der Molen and Pateron, 1979; Bagdassarov and Dorfman, 1998; Lejeune and Richet, 1995; Vigneresse et al., 1996; Rosenberg and Handy, 2005; Sato, 2005; Caricchi et al., 2007; Ishibashi and Sato, 2007; Champallier et al., 2008; Ishibashi, 2009; Mueller et al., 2010]. For suspensions made of nearly isometric particles such as quartz, values of $\phi_{\mathrm{c}}$ range from 0.3 [Saar et al., 2001] to 0.5 [Caricchi et al., 2007]. Ishibashi and Sato [2007] have demonstrated that the application of the Einstein-Roscoe equation remains relevant for $\phi_{\mathrm{s}}<0.3$ in the case of moderately anisometric particles with aspect ratios (length/width) less than 6.5. In contrast, Saar et al. [2001] have found numerically that, under static conditions (i.e., without fluid dynamics), the value of $\phi_{c}$ can vary from 0.08 to 0.2 for elongated particles with aspect ratios (width/height/length) from $1: 4: 16$ to $1: 1: 2$, respectively. Picard et al. [2011] showed experimentally that magmatic suspensions of anisometric plagioclase (length/width $=4$ ) have viscosities around 5 orders of magnitude higher than suspensions of equivalent crystallinities made of isometric particles such as quartz.

[3] In this study, new rheological and microstructural data are provided for plagioclase suspensions. Compared with Picard et al. [2011], a much wider range of crystallinities, from 0.38 to 0.75 , is considered. From our results, the effects of the shape of plagioclase and strain rate on the mechanism of the rheological transition and value of the critical crystal fraction $\phi_{\mathrm{c}}$ can be determined.

\section{Experimental Procedure}

\subsection{Synthesis of the Suspensions}

[4] A series of five plagioclase-bearing magmatic suspensions with crystal fractions $\left(\phi_{\mathrm{s}}\right)$ ranging from 0.38 to 0.75 (surfacic fraction) were synthesized at high pressures and temperatures from a synthetic haplotonalitic glass supplied by Schott Co. [see Picard, 2009]. The composition of the glass, determined by electron microprobe analysis, is $68.45 \mathrm{wt} \%$ $\mathrm{SiO}_{2}, 19.37 \mathrm{wt} \% \mathrm{Al}_{2} \mathrm{O}_{3}, 7.90 \mathrm{wt} \% \mathrm{Na}_{2} \mathrm{O}$, and $3.44 \mathrm{wt} \%$ $\mathrm{CaO}$, corresponding to 16,67 , and 17 normative quartz $(\mathrm{Qz})$, albite (Ab), and anorthite (An) contents, respectively. Finely powdered glass (grain size $<90 \mu \mathrm{m}$ ) was loaded together with a certain amount of distilled water in a large gold capsule (inner diameter $22 \mathrm{~mm}$, length $40 \mathrm{~mm}$, and wall thickness $0.25 \mathrm{~mm}$ ), which was sealed by arc welding. Typical charges weighed $\sim 12 \mathrm{~g}$. The plagioclase-bearing suspensions were synthesized at $300 \mathrm{MPa}$ by annealing the experimental charges at subliquidus temperatures in an internally heated pressure vessel for 7 days. Four suspensions $\left(\phi_{\mathrm{s}}=0.38\right.$, $0.58,0.62$, and 0.75 ) were synthesized at either $800^{\circ} \mathrm{C}$ or $900^{\circ} \mathrm{C}$, the crystal fraction of the suspensions being controlled by adjusting the amount of water initially loaded in the capsule. The suspension with $\phi_{\mathrm{s}}=0.52$ resulted from a more complex synthesis procedure involving an initial annealing step at $1000^{\circ} \mathrm{C}$ for $1 \mathrm{~h}$, a cooling step to $800^{\circ} \mathrm{C}$ at $4^{\circ} \mathrm{C} / \mathrm{h}$, and a final annealing step at $800^{\circ} \mathrm{C}$ for 5 days. All plagioclase suspension synthesis experiments were quenched isobarically to prevent $\mathrm{H}_{2} \mathrm{O}$ exsolution from the interstitial melt. At the end of the experiment, capsules were weighed to check for leaks and run products were carefully extracted. They typically consist of dense glassy cylinders (height 3-4 cm and diameter $\sim 2 \mathrm{~cm}$ ). The cylinders were first cored to a diameter ranging between 10 and $15 \mathrm{~mm}$ and then sawed in small disks (height 4-10 $\mathrm{mm}$ ), which were used directly in the deformation experiments. A maximum of four disks could be prepared from the same cylinder.

\subsection{Characterization of the Suspensions}

[5] Synthetic cylinders were systematically examined by scanning electron microscopy (SEM), using the JEOL JSM-6400 instrument at ISTO, Orléans, operated under back-scattered electron mode. They comprise euhedral plagioclase crystals embedded in a residual silicic glass. A minor amount of gas bubbles, indicating $\mathrm{H}_{2} \mathrm{O}$-saturated conditions, is also present (Figure 1). Quartz occurs in small amounts $(<1 \%)$ in the most plagioclase-rich suspension $\left(\phi_{\mathrm{s}}=0.75\right)$. Examination of multiple samples from the same cylinder shows a homogeneous distribution at the scale of the whole charge. The crystallinities and textural characteristics (shape of plagioclase crystals) of each starting suspension were obtained from image analysis performed on multiple SEM microphotographs using the ImageJ software. Average surfacic crystal fractions (Table 1) underline their homogeneity in terms of the distribution of crystals. Plagioclases exhibit a tabular morphology, with a shape ratio $(R)$ mostly between 3.5 and 5, except for the suspension with $\phi_{\mathrm{s}}=0.62$, where $\mathrm{R}$ is close to 2.5 . For $\phi_{\mathrm{s}}=0.75$, the high crystal fraction leads to the formation of aggregates and the shape ratio of the crystals could not be determined.

[6] Plagioclases and glasses were analyzed by electron microprobe using the Cameca SX 50 at Orléans. Si, Al, Na, and $\mathrm{Ca}$ were analyzed using an acceleration voltage of 15 $\mathrm{kV}$, a counting time of $10 \mathrm{~s}$ on peak (10 s on background), and a sample current of $6 \mathrm{nA}$. For plagioclase crystals, a beam focused to 1-2 $\mu \mathrm{m}$ was used. Glasses were analyzed with a $6 \times 6 \mu \mathrm{m}$ beam. Plagioclases have anorthite contents between 0.34 and 0.22 (Table 1). The low standard deviations (for data obtained from either top, middle, or bottom of the cylinder) indicate that the crystals are chemically homogeneous in a given suspension. Anorthite in plagioclase progressively decreases on increasing the crystal fraction, from $0.33 \pm 0.01$ $\left(\phi_{\mathrm{s}}=0.38\right)$ to $0.22 \pm 0.01\left(\phi_{\mathrm{s}}=0.75\right)$, as expected for equilibrium crystallization of a progressively higher fraction of plagioclase from a melt of fixed composition.

[7] Only glasses from suspensions with $\phi_{\mathrm{s}}=0.38$ and 0.52 were analyzed by electron microprobe because of their relatively low crystal fractions. $\mathrm{Na}_{2} \mathrm{O}$ concentrations were found to be substantially lower (20-30\%) than expected even after correcting for the migration of sodium under the beam [Pichavant, 1987]. Therefore, glass compositions were calculated by mass balance, knowing the composition of the starting glass and the composition and proportion of plagioclase in each suspension. Compared with the starting glass, all interstitial glasses are enriched in normative quartz and depleted in normative anorthite. They are all rhyolitic, with a narrow range of $\mathrm{SiO}_{2}$ concentration, between 74 and 

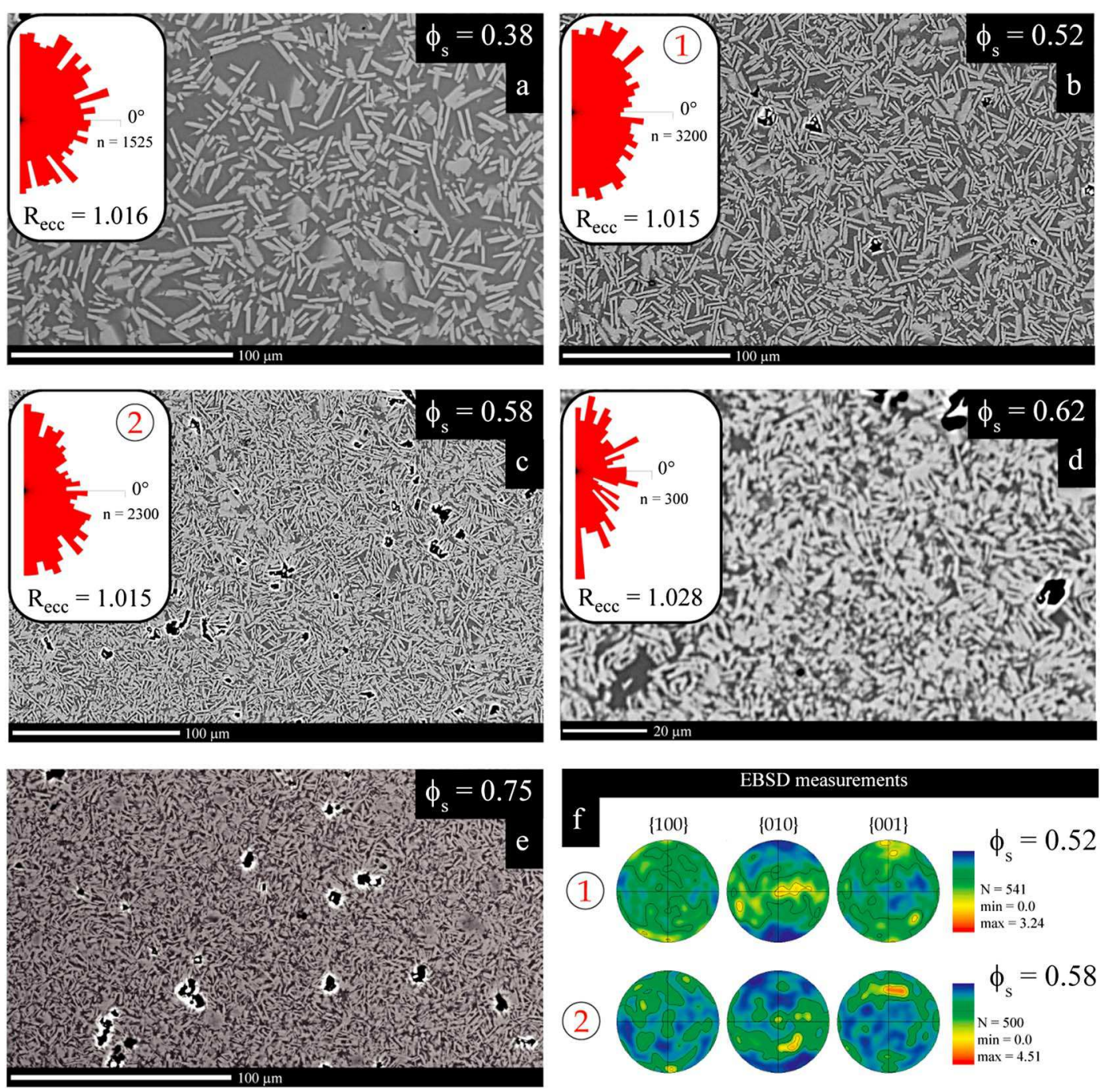

Figure 1. SEM images of the plagioclase-bearing suspensions before deformation (a-e). Plagioclase in light gray, silicic glass in dark gray, and gas bubbles in dark. (inset) Local plagioclase fabric long-axis orientations $(\alpha)$ displayed together on the rose diagram. Long-axis orientations $(\alpha)$ are positive and negative for an anticlockwise and a clockwise orientation, respectively. (f) Pole figures of the three plagioclase main crystallographic axes $(\{001\},\{010\}$, and $\{100\})$ are shown for the suspensions at $\phi_{\mathrm{s}}=0.52($ zone 1$)$ and $\phi_{\mathrm{s}}=0.58$ (zone 2).

$77 \mathrm{wt} \%$. For the most crystal-rich quartz-bearing suspension $\left(\phi_{\mathrm{s}}=0.75\right)$, the mass-balance calculations were adjusted by taking the glass composition as a fitting parameter. The glass composition estimated in this way is similar to the most $\mathrm{SiO}_{2}$-rich glasses $\left(77 \mathrm{wt} \% \mathrm{SiO}_{2}\right)$ in the other suspensions. These calculations also show that quartz is present in trace amounts (proportions $<0.5 \%$ by weight).

[8] The concentration of $\mathrm{H}_{2} \mathrm{O}$ in interstitial glasses was calculated using the $\mathrm{H}_{2} \mathrm{O}$ solubility model of Papale et al. [2006], knowing the glass composition and the experimental $\mathrm{P}$ and $\mathrm{T}$ conditions. Results range from 6.5 to $7.1 \mathrm{wt} \% \mathrm{H}_{2} \mathrm{O}$ (Table 1). Mass-balance calculations knowing the fraction of melt in the suspension $\left(=1-\phi_{\mathrm{s}}\right)$ and assuming that water present in the capsule is entirely dissolved into the melt also yield glass $\mathrm{H}_{2} \mathrm{O}$ concentrations in the same range $\left(6.1-8.1 \mathrm{wt} \% \mathrm{H}_{2} \mathrm{O}\right)$. This indicates a small amount of excess fluid during synthesis of the suspensions.

\subsection{Deformation Experiments}

[9] The rheological measurements were performed using the Paterson apparatus [Paterson and Olgaard, 2000] at Orléans, France. The disks prepared from the synthetic suspensions were inserted in a column assembly made of alumina and zirconia pistons enclosed in a hybrid jacket made of a middle copper part with bottom and top iron parts. The jacket was loaded inside the pressure vessel to place the sample in the isothermal zone of the furnace. The temperature gradient was stabilized to $<1^{\circ} \mathrm{C}$ across a length of $30 \mathrm{~mm}$. The length/diameter of the sample deformed in compression $(\sim 1)$ is relatively small compared with ratios used in compression tests $(\geq 2$; Hawkes and Mellor, [1970]). However, the low applied finite strain ensures a homogeneous no-slip deformation of the sample. The deformation experiments were performed at a confining pressure of $300 \mathrm{MPa}$ 
PICARD ET AL.: RHEOLOGICAL TRANSITION IN MAGMAS

Table 1. Morphological and Chemical Characteristics of the Plagioclases Suspensions

\begin{tabular}{|c|c|c|c|c|c|c|c|c|c|c|c|c|c|c|c|c|}
\hline \multirow[b]{2}{*}{$\begin{array}{l}\phi_{\mathrm{s}} \\
(\sigma)\end{array}$} & & \multirow[b]{2}{*}{ Run } & & \multirow[b]{2}{*}{$\begin{array}{c}\mathrm{a} \\
(\mu \mathrm{m})\end{array}$} & \multicolumn{5}{|c|}{ Plagioclases } & \multicolumn{7}{|c|}{ Glasses } \\
\hline & & & & & $\sigma$ & $\begin{array}{c}\mathrm{b} \\
(\mu \mathrm{m})\end{array}$ & $\sigma$ & $\mathrm{R}^{\mathrm{a}}$ & $\sigma$ & $A n^{b}$ & $\sigma$ & $\mathrm{Qtz}^{\mathrm{c}}$ & $A b^{c}$ & $A n^{c}$ & $\begin{array}{c}\mathrm{H}_{2} \mathrm{O} \\
\text { (wt. \%) }\end{array}$ & $\begin{array}{c}\eta_{\text {liq }} \\
(\log P a . s)\end{array}$ \\
\hline \multirow[t]{2}{*}{$0.38(0.01)$} & starting suspension & \#13 & & 5.61 & 4.67 & 1.96 & 1.37 & 3.56 & 1.84 & 0.33 & 0.01 & 24.5 & 69.0 & 6.5 & 7.1 & 3.08 \\
\hline & deformed suspension & PP070 & & 6.56 & 4.88 & 2.10 & 1.8 & 3.67 & 1.75 & 0.34 & 0.01 & 24.0 & 69.0 & 7.0 & 7.1 & \\
\hline \multirow[t]{3}{*}{$0.52(0.01)$} & starting suspension & \# 07 & & 6.19 & 5.23 & 1.82 & 1.85 & 4.05 & 1.96 & 0.29 & 0.01 & 28.0 & 66.5 & 5.5 & 6.7 & 4.01 \\
\hline & & $\mathrm{PPO42}$ & pervasive fabric & 6.40 & 3.26 & 1.84 & 1.01 & 3.75 & 1.67 & 0.27 & 0.01 & 26.5 & 68.0 & 5.5 & 6.7 & \\
\hline & deformed suspension & РP043 & shear zone & 6.16 & 3.34 & 1.54 & 0.58 & 4.08 & 1.75 & 0.29 & 0.01 & & & & & \\
\hline \multirow[t]{3}{*}{$0.58(0.01)$} & starting suspension & \# 06 & & 5.79 & 5.16 & 1.39 & 1.33 & 5.01 & 2.63 & 0.25 & 0.01 & 27.5 & 64.5 & 8.0 & 6.5 & 4.09 \\
\hline & & $\mathrm{PP} 03$ & pervasive fabric & 5.28 & 1.77 & 1.09 & 0.17 & 4.81 & 1.79 & 0.24 & 0.01 & 24.5 & 66.5 & 9.0 & 6.5 & \\
\hline & deformed suspension & PPO50 & shear zone & 2.18 & 0.55 & 0.68 & 0.33 & 2.84 & 1.23 & 0.24 & 0.01 & & & & & \\
\hline \multirow[t]{2}{*}{$0.62(0.01)$} & starting suspension & $\# 16$ & & 1.79 & 0.59 & 0.67 & 0.18 & 2.59 & 0.63 & 0.23 & 0.01 & 29.5 & 62.5 & 8.0 & 6.6 & 4.15 \\
\hline & deformed suspension & PP086 & & 2.10 & 0.58 & 0.83 & 0.31 & 2.42 & 0.69 & 0.24 & 0.01 & 29.0 & 63.5 & 7.5 & 6.6 & \\
\hline \multirow[t]{2}{*}{$0.75(0.01)$} & starting suspension & & & / & l & / & l & / & l & 0.23 & 0.01 & 29.8 & 62.8 & 7.4 & 6.6 & 4.15 \\
\hline & deformed suspension & PP081 & & l & / & l & / & l & l & 0.22 & 0.01 & & & & & \\
\hline
\end{tabular}

$\mathrm{a}$ is the length of the crystals, $\mathrm{b}$ the width and $\mathrm{R}$ the shape ratio. $\sigma$ is the standard deviation. $\mathrm{H}_{2} \mathrm{O}$ is the water concentration of the glass, estimated using the by-difference method.

${ }^{\mathrm{a}} \mathrm{R}=\left(\sum \mathrm{O}_{\mathrm{i}} \mathrm{a}_{\mathrm{i}} / \mathrm{b}_{\mathrm{i}}\right) / \mathrm{i}$ with $\mathrm{i}=$ number of analysed crystals

${ }^{\mathrm{b}} \mathrm{An}=$ atomic $\mathrm{Ca} /(\mathrm{Ca}+\mathrm{Na})$ of plagioclase crystals determined from electron microprobe analyses

${ }^{\mathrm{c}} \mathrm{Qtz}, \mathrm{Ab}, \mathrm{An}=$ normative quartz, albite and anorthite contents of the glasses, calculated from electron microprobe analyses

and temperatures of $900^{\circ} \mathrm{C}$ and $800^{\circ} \mathrm{C}$, identical to the $\mathrm{P}$ and $\mathrm{T}$ conditions of synthesis of the suspensions, and for strain rates of $1.0 \times 10^{-5}$ to $1.0 \times 10^{-3} \mathrm{~s}^{-1}$. Suspensions ranging from $\phi_{\mathrm{s}}=0.52$ to 0.75 were deformed in torsion, whereas, for lower crystal fraction $\left(\phi_{\mathrm{s}}=0.38\right)$, the viscosity of the suspension was too low and samples needed to be deformed in compression [Picard et al., 2011]. All experiments were performed at constant applied strain rates (either $\dot{\varepsilon}$ in compression or $\dot{\gamma}$ in torsion), measuring the stress (either $\sigma$ in compression or $\tau$ in torsion) of the sample as a function of strain (either compressional $\varepsilon$ or shear $\gamma$ in torsion). To compare the apparent viscosities obtained in torsion and compression, compressive strain rates and stresses were converted to shear strain rates and stresses by using Eqs. (38)-(40) from Paterson and Olgaard [2000]:

$$
\begin{aligned}
\dot{\varepsilon}_{\text {eff }} & =\dot{\varepsilon}_{1} \text { in the axial test }, \\
\dot{\varepsilon}_{\text {eff }} & =\frac{1}{\sqrt{3}} \dot{\gamma} \text { in the torsion test }, \text { and } \\
\sigma & =\sqrt{3} \tau .
\end{aligned}
$$

[10] For suspensions with $\phi_{\mathrm{s}}=0.52$ and 0.58 , each experiment was performed at a different (and constant) strain rate, whereas, for $\phi_{\mathrm{s}}=0.38,0.62$, and 0.75 , a stepping strain rate procedure was preferred. It consists in varying the strain rate in a stepwise manner during the same experiment, once steady-state stress conditions have been achieved.

[11] For the compression experiments, a specific high sensitivity load cell was used to monitor the displacement with a resolution of $1 \mu \mathrm{m}$ and the applied stress (from 10 to $10^{2} \mathrm{~N}$ ) with a resolution of $0.1 \mathrm{~N}$. For the torsion experiments, the load cell monitored the displacement with a resolution of $10^{-2}$ radian and the torque (from 1 to $10^{2} \mathrm{~N} \mathrm{~m}$ ) with a resolution of $0.1 \mathrm{~N} \mathrm{~m}$. A correction for the deformation of the copper jacket was applied. All measured torques (in torsion) and applied force (in compression) were corrected using equations given by Paterson and Olgaard [2000], which use rheological parameters for copper metal from Frost and Ashby [1982], as

$$
\begin{gathered}
\mathrm{M}=\frac{\pi \tau}{4\left(3+\frac{1}{n}\right)} \times \frac{d_{o}^{(3+1 / n)}-d_{i}^{(3+1 / n)}}{d_{o}^{(1 / n)}} \text { in torsion } \\
\text { with } \tau=\left(\frac{\dot{\gamma}}{A \exp (-Q / R T)}\right)^{\frac{1}{n}}
\end{gathered}
$$

and

$$
\begin{gathered}
F=\pi \sigma \times\left(\left(\frac{d_{0}}{2}\right)^{2}-\left(\frac{d_{i}}{2}\right)^{2}\right) \text { in compression } \\
\text { with } \sigma=\left(\frac{\dot{\varepsilon}}{A \exp (-Q / R T)}\right)^{\frac{1}{n}}
\end{gathered}
$$

where $\mathrm{M}$ and $\mathrm{F}$ are the torque and the force of the jacket, respectively; $d_{i}$ and $d_{o}$ are the inner and outer diameters of the jacket, respectively; $\mathrm{n}$ is the exponent of the metal; $\tau$ is the shear stress; $\sigma$ is the axial stress; $A$ is a pre-exponential term; $\mathrm{Q}$ is the energy of activation; $\mathrm{R}$ is the gas constant; and $\mathrm{T}$ is the temperature.

\subsection{Characterization of the Deformed Samples}

[12] The microstructures developed as a result of the deformation experiments were observed optically and with a SEM. Thin sections were cut along the diameter, parallel to the length of the sample ([YZ] plane, with $\mathrm{Z}$ parallel to the compression axis) in compression and normal to the radius of the core of the sample ([XZ] plane, with [XY] the plane of shear and $\mathrm{X}$ the direction of shear) in torsion. The shape fabric of the crystals was analyzed with the intercept method (Intercept2003 software) [Launeau and Robin, 1996]. It gives the eccentricity of the fabric ellipse $\left(\mathrm{R}_{\mathrm{ecc}}\right)$, which corresponds to the fabric intensity, and the long-axis orientation $(\alpha)$, which corresponds to the maximum density of the fabric ellipse. The latter is positive or 
negative for an anticlockwise or a clockwise orientation, respectively. $\alpha=0^{\circ}$ is equivalent to a fabric ellipse parallel to the shear direction in torsion and perpendicular to the direction of shortening in compression experiments. In practice, each SEM image was subdivided in overlapping subwindows (typically $20 \times 20$ ), which were then analyzed individually for their local plagioclase fabric. All long-axis orientations were then displayed together on a rose diagram. For suspensions with $\phi_{\mathrm{s}}=0.52$ and $\phi_{\mathrm{s}}=0.58$, the 2-D shape fabric obtained by the intercept method was compared with the 3-D crystallographic preferred orientation (CPO) of plagioclase measured with the electron back-scattered diffraction (EBSD) technique [Heidelbach et al., 2000]. The data are given directly as poles figures of the three crystallographic planes $\{001\},\{010\}$, and $\{100\}$.

\section{Results}

\subsection{Initial Textures}

[13] To check for the presence of initial textures developed during synthesis, the starting suspensions were characterized with the same procedures as above for the deformed suspensions. All starting suspensions with crystal fractions $\phi_{\mathrm{s}}<0.58$ show a very weak shape fabric, with no significant preferred orientation, as revealed by the nearly random distribution of the long-axis orientations on the rose diagrams, and the very low eccentricities $\mathrm{R} \sim 1.015$ (Figure 1a-c). For $\phi_{\mathrm{s}}=0.62$, a slight preferred orientation develops parallel to the $\mathrm{Z}$ plane and is associated with an increasing eccentricity $\mathrm{R}$ of 1.028 (Figure $1 \mathrm{~d}$ ). This eccentricity, calculated on a limited number of images, could result from the difficulty to separate the plagioclase crystals that form aggregates surrounded by the interstitial glass. For the highest crystal fraction $\left(\phi_{\mathrm{s}}=0.75\right)$, contacts between the crystals become too important, and this prevents the orientation of the crystal fabric to be analyzed with the intercept method.

[14] The CPO of the plagioclases in the starting suspensions with $\phi_{\mathrm{s}}=0.52$ and 0.58 show a dispersed girdle of $\{010\}$ poles in the shear plane with a maximum close to the center of the pole figure and a dispersed orientation of the $\{001\}$ and $\{100\}$ poles with a maximum perpendicular to the shear direction (Figure 1f). This indicates a weak plano-linear crystallographic fabric in the [XZ] plane.

\subsection{Mechanical Behavior}

[15] The rheological behavior of the suspensions with $\phi_{\mathrm{s}}=$ 0.38 and 0.52 have been described by Picard et al. [2011]. For $\phi_{\mathrm{s}}=0.38$ and at $\varepsilon<0.5$, the differential stress (stress correcting from the strength of the jacket) increases linearly with strain (Figure 2a) corresponding to the relaxation of the sample. For higher strain, this elastic domain is followed by a plastic behavior characterized by a nearly constant differential stress (Figure 2a). Two steps from the same experiment at high strain rates $\left(\dot{\varepsilon} \sim 8 \times 10^{-4} \mathrm{~s}^{-1}\right)$ show similar rheological behavior, demonstrating the reproducibility of our results in compression. For $\phi_{\mathrm{s}}=0.52$, the elastic domain is followed by a short stress plateau $\gamma$ between $\sim 0.1$ and $\sim 0.4$. At higher strains, the differential stress decreases progressively until the maximum applied strain $(\gamma=1.4)$, indicating a strain weakening behavior (Figure 2b).
[16] For $\phi_{\mathrm{s}}=0.58$, and for the four strain rates investigated, the differential stress increases to a peak at $\gamma=0.1$. In contrast to what is observed for the $\phi_{\mathrm{s}}=0.52$ suspensions, all peaks are immediately followed by an important stress weakening until $\gamma \approx 0.6$ (Figure $2 \mathrm{c}$ ). For higher shear strains, a tendency to stabilization of the stress is observed (steady-state behavior). The two experiments performed at the same high strain rates $\left(\dot{\varepsilon} \sim 9.5 \times 10^{-4} \mathrm{~s}^{-1}\right)$ show a similar rheological behavior, which again confirms the reproducibility of the experiments, in this case in torsion (Figure 2c).

[17] At high crystal fractions $\left(\phi_{\mathrm{s}}=0.62\right.$ and 0.75$)$, all experiments performed at different strain rates show a stabilization of the stress at $\gamma>0.04$ (Figure $2 \mathrm{~d}$ and e). For all crystal fractions, the higher the strain rate, the higher the stress.

\subsection{Stress Exponents and Apparent Viscosities}

[18] The rheology of our experimental magmatic suspensions can be been fitted with power-law equations of the form (Figure 3):

$$
\dot{\gamma}=C \tau^{n}
$$

in torsion and

$$
\dot{\varepsilon}=C \sigma^{n}
$$

in compression

$$
\text { with } C=\mathrm{A} \exp (-\mathrm{Q} / \mathrm{RT}) \text {, }
$$

where $\mathrm{A}$ is a pre-exponential term, $\mathrm{Q}$ is the energy of activation, $\mathrm{R}$ is the gas constant, and $\mathrm{T}$ is the temperature. $\mathrm{C}$ is an empirical parameter determined from the fit of the data (Figure 3). The stress exponent $n$ is obtained from the slope of the data in either $\log \dot{\varepsilon}$ versus $\log \sigma$ (compression) or $\log \dot{\theta}$ versus $\log \mathrm{M}$ (torsion, where $\dot{\theta}$ is the angular rate and $\mathrm{M}$ is the applied torque) [Paterson and Olgaard, 2000]. Values of $n$ range from 2.7 to 4.1 (Table 1). This demonstrates a non-Newtonian, shear thinning, rheological behavior for our plagioclase suspensions (pseudo-plastic materials).

[19] It is to notice that the equations above do not incorporate a yield strength term. Yet, it has been shown that a yield strength may appear at high crystallinities once a crystal network develops [Ryerson et al., 1988; Pinkerton and Stevenson, 1992]. However, the precise determination of a yield strength would require data at very low stresses. In our study, the experiments were all run at relatively high strain rates and there is no need for a more complex power law.

[20] The apparent viscosities of each suspension $\eta_{\text {app }}$ are usually calculated when stress become constant. Nevertheless, it never does in our experiments. Thus, we calculated $\eta_{\text {app }}$ using the maximum stress $\sigma$ and $\tau$, and the strain rate $\dot{\varepsilon}$ and $\dot{\gamma}$, using

$$
\eta_{\text {app }}=\tau / \dot{\gamma}
$$

in torsion and

$$
\eta_{\text {app }}=\sigma / \dot{\varepsilon}
$$

in compression.

[21] All calculated apparent viscosities are summarized in Table 2. For each crystal fraction, the apparent viscosities decrease by $\sim 1.5$ order of magnitude at $\dot{\gamma}=1.0 \times 10^{-5}$ 

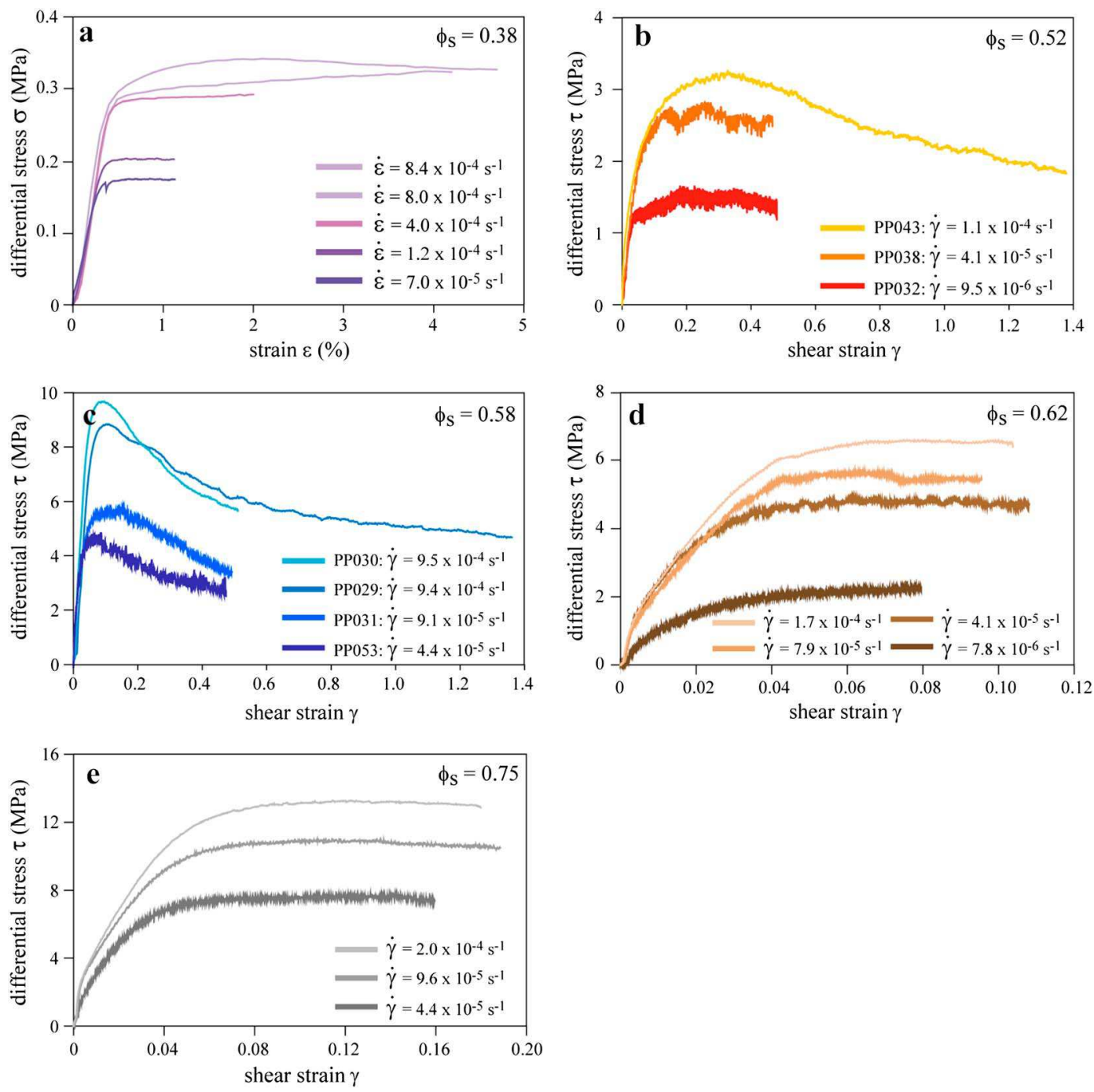

Figure 2. Rheological curves obtained at $\phi_{\mathrm{s}}=0.38$ in compression (a) and at $\phi_{\mathrm{s}}=0.52-0.75$ in torsion $(\mathrm{b}-\mathrm{e})$ at different strain rates as indicated. Experiments at $\phi_{\mathrm{s}}=0.38,0.62$, and 0.75 are stepping strain experiments (a, d, and e).

to $1.0 \times 10^{-3} \mathrm{~s}^{-1}$, which is characteristic of a shear thinning behavior (Figure 4). In addition, for a given strain rate, the higher the crystal fraction, the higher the viscosity. For example, at $\dot{\gamma} \sim 1.0 \times 10^{-4} \mathrm{~s}^{-1}, \log \eta_{\text {app }}$ increases from 8.73 to $11.00 \mathrm{~Pa}$ s for $\phi_{\mathrm{s}}=0.38$ to 0.75 .

\subsection{Microstructures and Compositions of the Deformed Suspensions}

3.4.1. 2-D Shape Preferred Orientations of Plagioclase [22] For the suspension with $\phi_{\mathrm{s}}=0.38$, the orientation $(\alpha)$ that describes the shape fabric of the crystals is of up $0^{\circ}$ and it is coupled with an increase of the eccentricity $\left(R_{e c c}\right)$ close to 1.1 in the middle part of the sample (Figure 5a). Local measurements confirm a pervasive fabric oriented at $\sim 0^{\circ}$ (Figure 6a). No discrete structures, such as shear zones or bands, are observed. Plagioclase crystals have their morphologic characteristics unchanged within error compared with those measured in the initial textures (Table 1). Electron microprobe analyses of plagioclase and residual glasses from the deformed suspensions do not vary from those analyzed in the starting suspensions (Table 1).
[23] For $\phi_{\mathrm{s}}=0.52$ and in the upper and lower part of the samples, the orientation $(\alpha)$ is close to $90^{\circ}$ and it is associated with a low eccentricity $\left(\mathrm{R}_{\mathrm{ecc}}\right)$ close to 1.05 (Figure $\left.5 \mathrm{~b}\right)$. These values, similar to those observed for the undeformed suspensions, indicate that the upper and lower parts of the samples were not significantly deformed most probably because the applied stress was not transmitted in these two zones. In the middle part of the samples, the orientation strongly differs from that in the starting suspensions, being close to $45^{\circ}$ and it is associated with a slight increase of $R_{\text {ecc }}$ with the strain rate (Figure $5 \mathrm{~b}$ ). This strong pervasive shape fabric is cross-cut by shear zones oriented at $-20^{\circ}$ relative to the shear direction. They are bordered by symmetrical shear gradients indicating a dextral sense of shear, synthetic to the bulk deformation (Figure 6b). The development and evolution of these bands are directly dependent of the applied strain rates (Figure 7a). With increasing the strain rate, the number of shear bands increases (from no shear band at $\dot{\gamma}=1.10^{-5} \mathrm{~s}^{-1}$ to six at $1.10^{-4} \mathrm{~s}^{-1}$ ), whereas their thickness $(30-40 \mu \mathrm{m})$ stays approximately constant. The fabric inside the shear zone is oriented close to the bulk shear direction, 


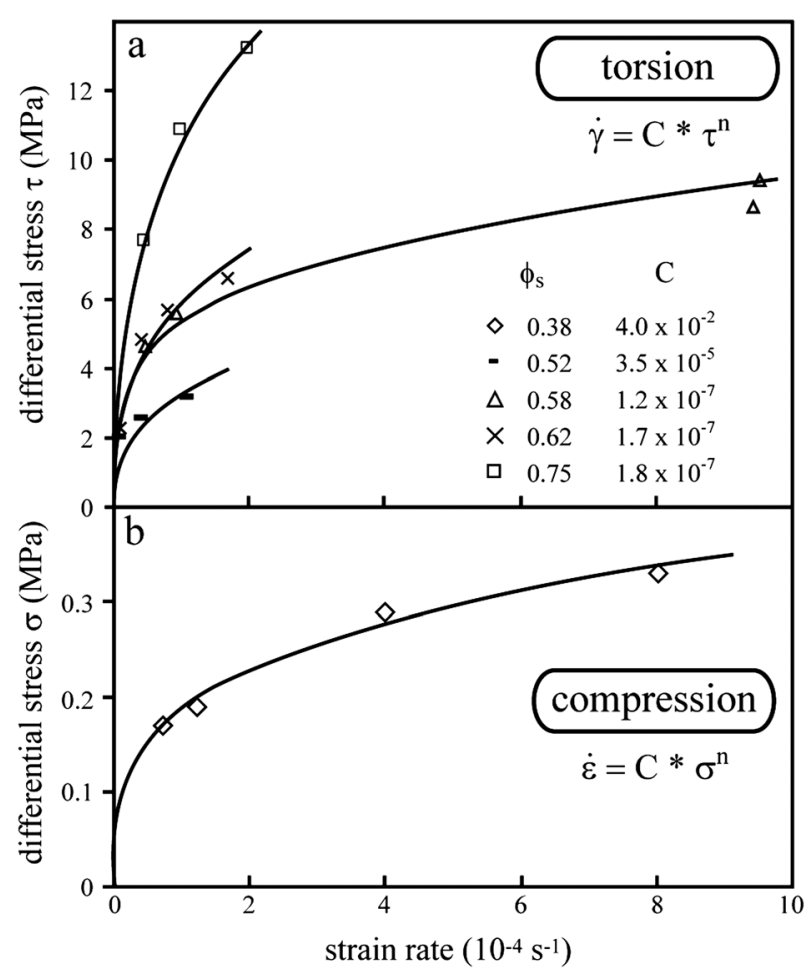

Figure 3. Stress versus strain in torsion (a) and compression (b). Data were fitted using a power law equation (Eqs. (8) and (9); Table 2).

Table 2. Viscosity Data

\begin{tabular}{|c|c|c|c|c|c|c|}
\hline \multicolumn{7}{|c|}{ Compression experiments } \\
\hline Run & $\phi_{\mathrm{s}}$ & $n$ & strain rate & $\log \eta_{\mathrm{app}}$ & $\log \eta_{\text {liq }}$ & $\log \eta_{\mathrm{r}}$ \\
\hline & & & $\left(\mathrm{s}^{-1}\right)$ & (Pa.s) & (Pa.s) & (Pa.s) \\
\hline \multirow[t]{5}{*}{ PP070 } & 0.38 & 3.6 & $7.0 \times 10^{-5}$ & 8.91 & 3.08 & 5.83 \\
\hline & & & $1.2 \times 10^{-4}$ & 8.73 & & 5.65 \\
\hline & & & $4.0 \times 10^{-4}$ & 8.38 & & 5.30 \\
\hline & & & $8.0 \times 10^{-3}$ & 8.10 & & 5.02 \\
\hline & & & $8.4 \times 10^{-3}$ & 8.14 & & 5.06 \\
\hline \multicolumn{7}{|c|}{ Torsion experiments } \\
\hline PP066 & 0.38 & l & $9.9 \times 10^{-4}$ & not measurable & 3.8 & not measurable \\
\hline PP032 & 0.52 & 2.8 & $9.5 \times 10^{-6}$ & 11.20 & 4.01 & 7.19 \\
\hline PP038 & & & $4.1 \times 10^{-5}$ & 10.83 & & 6.82 \\
\hline PP043 & & & $1.1 \times 10^{-4}$ & 10.49 & & 6.48 \\
\hline PP053 & 0.58 & 4.1 & $4.4 \times 10^{-5}$ & 11.01 & 4.09 & 6.92 \\
\hline PP031 & & & $9.1 \times 10^{-5}$ & 10.78 & & 6.69 \\
\hline PP030 & & & $9.4 \times 10^{-4}$ & 10.10 & & 6.01 \\
\hline PP029 & & & $9.5 \times 10^{-4}$ & 9.96 & & 5.87 \\
\hline \multirow[t]{4}{*}{ PP086 } & 0.62 & 2.8 & $7.8 \times 10^{-6}$ & 11.46 & 4.15 & 7.31 \\
\hline & & & $4.1 \times 10^{-5}$ & 11.07 & & 6.92 \\
\hline & & & $7.9 \times 10^{-5}$ & 10.85 & & 6.70 \\
\hline & & & $1.7 \times 10^{-4}$ & 10.60 & & 6.45 \\
\hline \multirow[t]{3}{*}{ PP081 } & 0.75 & 2.7 & $4.4 \times 10^{-5}$ & 11.23 & & \\
\hline & & & $9.6 \times 10^{-5}$ & 11.00 & & \\
\hline & & & $2.0 \times 10^{-4}$ & 10.80 & & \\
\hline
\end{tabular}

with a preferred orientation of crystals at approximately $-3^{\circ}$ relative to the shear direction. The orientation of the crystals inside the shear bands is always parallel to the bulk shear direction and not to the border of the shear band. Plagioclase crystals in the starting materials, and both inside and outside of the shear zone, have the same size and aspect ratio dispersion and chemical composition (Table 1).

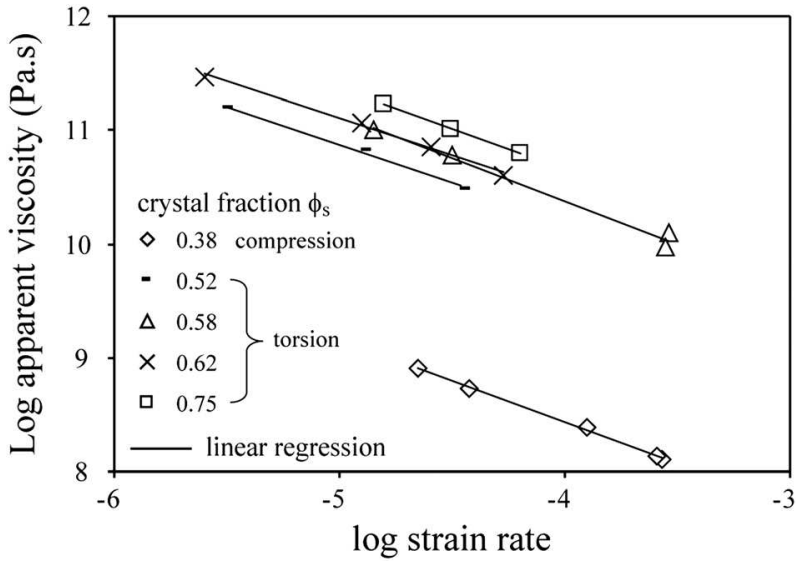

Figure 4. Apparent viscosity versus strain rate for all experiments. Lines are best fit for all crystal fractions.

[24] For $\phi_{\mathrm{s}}=0.58$, a very low eccentricity $(<1.05)$ all over the $[\mathrm{XZ}]$ section and an orientation subperpendicular to the shear direction is evidenced for all strain rates (Figure 5c). Such an eccentricity is comparable with those measured in the undeformed suspensions and indicates that the initial pervasive fabric acquired during synthesis of the sample has not been deformed. This preserved initial fabric is cross-cut by $50 \pm 10 \mu \mathrm{m}$ thick, shear zones oriented at approximately $-10^{\circ}$. They are not bordered by shear gradients (Figure 6c). These zones are well established for the PP030 experiment (Figure 5c) and they mostly correspond to values close to $0^{\circ}$ and $180^{\circ}$. At this crystal fraction, the thicknesses of the bands increase (from $40 \mu \mathrm{m}$ at $4.4 \times 10^{-5} \mathrm{~s}^{-1}$ to a maximum of $120 \mu \mathrm{m}$ at $\left.8.9 \times 10^{-4} \mathrm{~s}^{-1}\right)$, whereas the spaces between them stay constant (Figure $7 b$ ). The shape fabric inside the shear zones is oriented close to the shear direction, with a preferred orientation at $\sim 3^{\circ}$ relative to the shear direction. Plagioclase crystals inside the shear zones show significant size and aspect ratio reductions compared with those outside the shear band. Yet, composition inside and outside the shear zones are the same $(\mathrm{An}=0.24)$ and identical within error to the anorthite content of plagioclase in the starting suspension $(0.25$; Table 1$)$.

[25] For $\phi_{\mathrm{s}}=0.62$, the fabric orientation is close to $65^{\circ}$ and coupled with a weak eccentricity close to 1.05 (Figure $5 \mathrm{~d}$ ), which is again similar to those obtained for the suspension before deformation. No shear bands cross-cutting this welloriented pervasive fabric were observed (Figure 6d).

[26] For $\phi_{\mathrm{s}}=0.75$, the high proportion of crystals leads to dense solid aggregates (Figure 6e), which prevent the application of the intercept method and the shape preferred orientation (SPO) in those suspensions is undetermined.

\subsubsection{3-D CPOs of Plagioclase}

[27] CPOs have been determined in two suspensions deformed in torsion $\left(\phi_{\mathrm{s}}=0.52\right.$ and 0.58$)$. In both cases, zones corresponding to the pervasive fabrics and to the shear bands were investigated.

[28] In the suspension with $\phi_{\mathrm{s}}=0.52$, the CPO of the plagioclases in the pervasive fabric shows a maximum concentration of $\{010\}$ poles at $\sim 45^{\circ}$ anticlockwise with respect to the shear plane and girdles of $\{001\}$ and $\{100\}$ at $\sim 50^{\circ} / 60^{\circ}$ clockwise (Figure 6b, zone 1). This indicates a dominantly planar fabric, with the trace of the $\{010\}$ crystallographic 

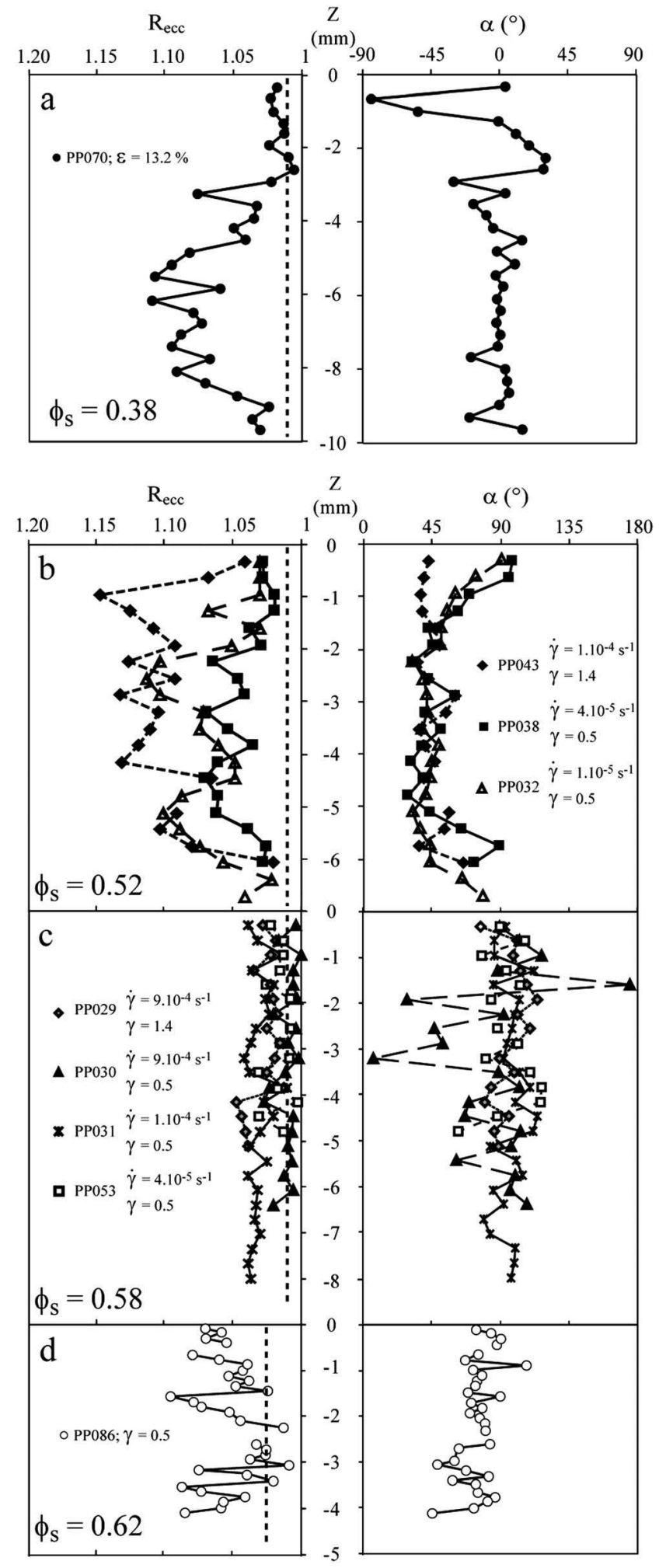

Figure 5. Evolution of the eccentricity $\mathrm{R}_{\mathrm{ecc}}$ and the longaxis orientation $(\alpha)$ versus the length of the samples deformed in compression (a) and in torsion (b-d) at different strain rates, as indicated. (dashed lines) Values of $\mathrm{R}_{\mathrm{ecc}}$ for the suspensions before deformation.

plane in the $[\mathrm{XZ}]$ plane oriented near $45^{\circ}$ clockwise, similar to $\alpha\left(45^{\circ}\right)$. In the shear zone, the plagioclases $\{010\}$ poles are oriented perpendicular to the bulk shear plane, as observed from the shape fabric. Both the $\{001\}$ and the $\{100\}$ pole figures show a girdle parallel to the shear plane, with a maximum close to the bulk shear direction, defining a plano-linear crystallographic fabric (Figure $6 b$, zone 2).

[29] For $\phi_{\mathrm{s}}=0.58$, the CPO of the plagioclases in the pervasive fabric (Figure 6c, zone 3 ) shows a girdle of $\{010\}$ poles in the shear plane and $\{001\}$ and $\{100\}$ oriented perpendicular to the shear plane. Despite the limited number of measurements, a CPO fabric is obvious in the shear zone with $\{010\}$ poles oriented perpendicular to the shear plane and $\{001\}$ and $\{100\}$ poles show a girdle in the shear plane (Figure 6c, zone 4).

\section{Discussion}

\subsection{Rheological Behavior of Magmatic Suspensions: Influence of the Plagioclase Content}

[30] The rheological behavior of the studied plagioclase suspensions, together with the microstructural evolution, can be represented on a large domain of crystallinity $\left(0<\phi_{\mathrm{s}}<0.75\right.$; Figure 8$)$.

[31] For $\phi_{\mathrm{s}}<0.2$, we define the domain I in which the viscosity is calculated using the Einstein-Roscoe equation by taking a viscosity for our melt $\left(\eta_{0}\right)$ of $10^{3.44} \mathrm{~Pa} \mathrm{~s}$, an exponent (n) of 2.5 and a maximum packing fraction $\left(\phi_{\max }\right)$ of 0.62 (value for a random arrangement) [Chong et al., 1971]. The viscosity of $10^{3.44} \mathrm{~Pa} \mathrm{~s}$ of the melt $\left(\phi_{\mathrm{s}}=0\right)$ is calculated from the equation of Giordano et al. [2008] by using the chemical composition of the starting glass at $850^{\circ} \mathrm{C}$ and for $6.5 \%$ dissolved water. We selected these values because they correspond to the average of the temperature and water content ranges explored in this study. In domain I, the magmatic suspensions are assumed to have a Newtonian behavior [Fernandez and Gasquet, 1994; Lejeune and Richet, 1995; Ishibashi and Sato, 2007].

[32] For $0.2<\phi_{\mathrm{s}}<\sim 0.38$, a domain II is evidenced from experiment PP070 (Figure 6a). It is characterized by a strong increase of the apparent viscosity compared with those calculated from the Einstein-Roscoe equation and by a steady-state plastic flow (Figure 8). In this domain, the effect of the solid fraction becomes predominant and the plagioclase suspensions exhibit a non-Newtonian, shear thinning behavior (Figure 4; Table 2). The interconnectivity between crystals generates a solid network able to transmit stress and leads to a strong increase of the apparent viscosity of $\sim 6$ orders of magnitude, from $10^{4}$ to $10^{10} \mathrm{~Pa} \mathrm{~s}$. This rheological behavior and the associated unimodal fabrics found for the domain II are consistent with results obtained on previous studies [Lejeune and Richet, 1995; Rosenberg and Handy, 2005; Caricchi et al., 2007; Picard et al., 2011] and match the Rigid Percolation Threshold defined by Vigneresse et al. [1996]. At these low crystal fractions, suspensions can accommodate the deformation by crystal rotation and translation [Fernandez et al., 1983; Ildefonse et al., 1992a, 1992b; Ježek et al., 1994; Arbaret et al., 1996, 1997; Fernandez and Fernandez-Catuxo, 1997; Arbaret et al., 2007]. A well-oriented pervasive fabric develops (Figure 6a) and leads to the stabilization of the stress with increasing strain, as observed (Figure 2a).

[33] For $0.38<\phi_{\mathrm{s}}<0.58$, weakening by strain localization defines the domain III (Figure 8). The crystal fraction reduces the capability of the solid network to accommodate the deformation by crystal rotation and translation. Thus, strain partitioning occurs with the development of discrete 

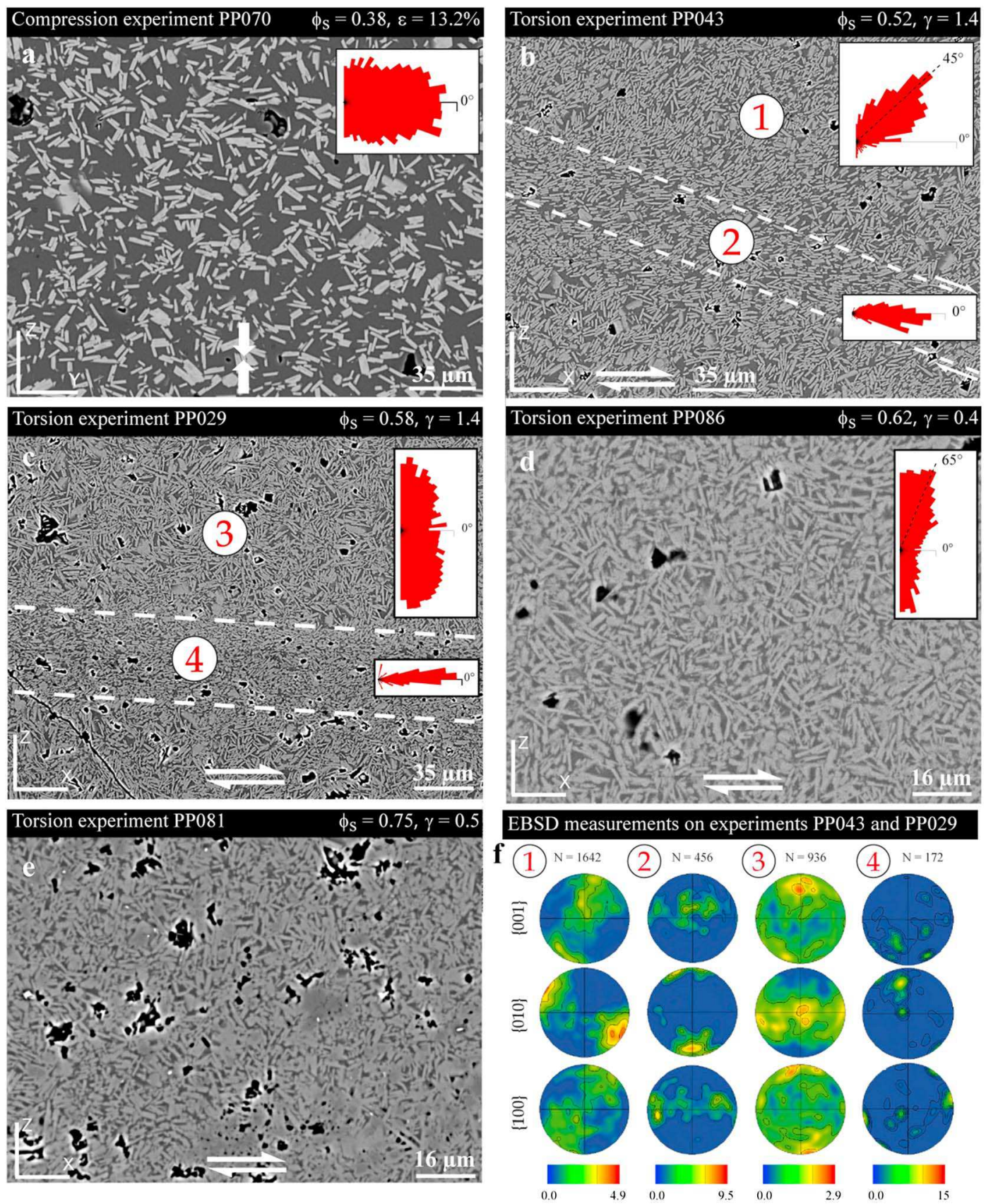

Figure 6. Microstructures of plagioclase-bearing suspensions deformed in compression (a) and in torsion (b-e). (left) Plagioclase in light gray, silicic glass in dark gray, and gas bubbles in dark. The shear bands are delimited by dashed lines. (white arrows) Type of deformation. Pervasive fabrics and shear bands at $\phi_{\mathrm{s}}=0.52$ and 0.58 are zones 1 and 3 and zones 2 and 4, respectively. (inset) The long axes of the local (i.e., for each subwindow) crystal fabric are displayed together in the rose diagram. Pole figures of the three plagioclase main crystallographic axes $(\{001\},\{010\}$, and $\{100\})$ measured with the EBSD technique for sample PP043 (b) and PP029 (c). Zones 1 and 3 correspond to CPO of pervasive fabrics, whereas zones 2 and 4 are CPO measured in shear localized bands. Dextral shear direction is horizontal with plane of shear normal to the figure.

structures [Smith, 1996, 1997; Vigneresse and Tikoff, 1999; Arbaret et al., 2007; Picard et al., 2011]. Two successive subdomains are defined as a function of the type of discrete structures developed in response of the applied strain. The subdomain IIIa corresponds to the lowest crystal fraction $\left(\phi_{\mathrm{s}}=0.52\right.$; PP043; Figure $\left.6 \mathrm{~b}\right)$ and is characterized by the development of $\mathrm{S} / \mathrm{C}$-like structures. The subdomain
IIIb corresponds to the highest crystal fraction $\left(\phi_{\mathrm{s}}=0.58\right.$; PP029; Figure 6c) and is characterized by a strong strain weakening. 2-D shape fabric and 3-D CPO measurements have determined that the primary pervasive fabric of the suspension has not undergone deformation. In addition, the 3-D CPO are similar to the 2-D SPO obtained with the intercept method. This indicates that the observed plagioclase axes in 


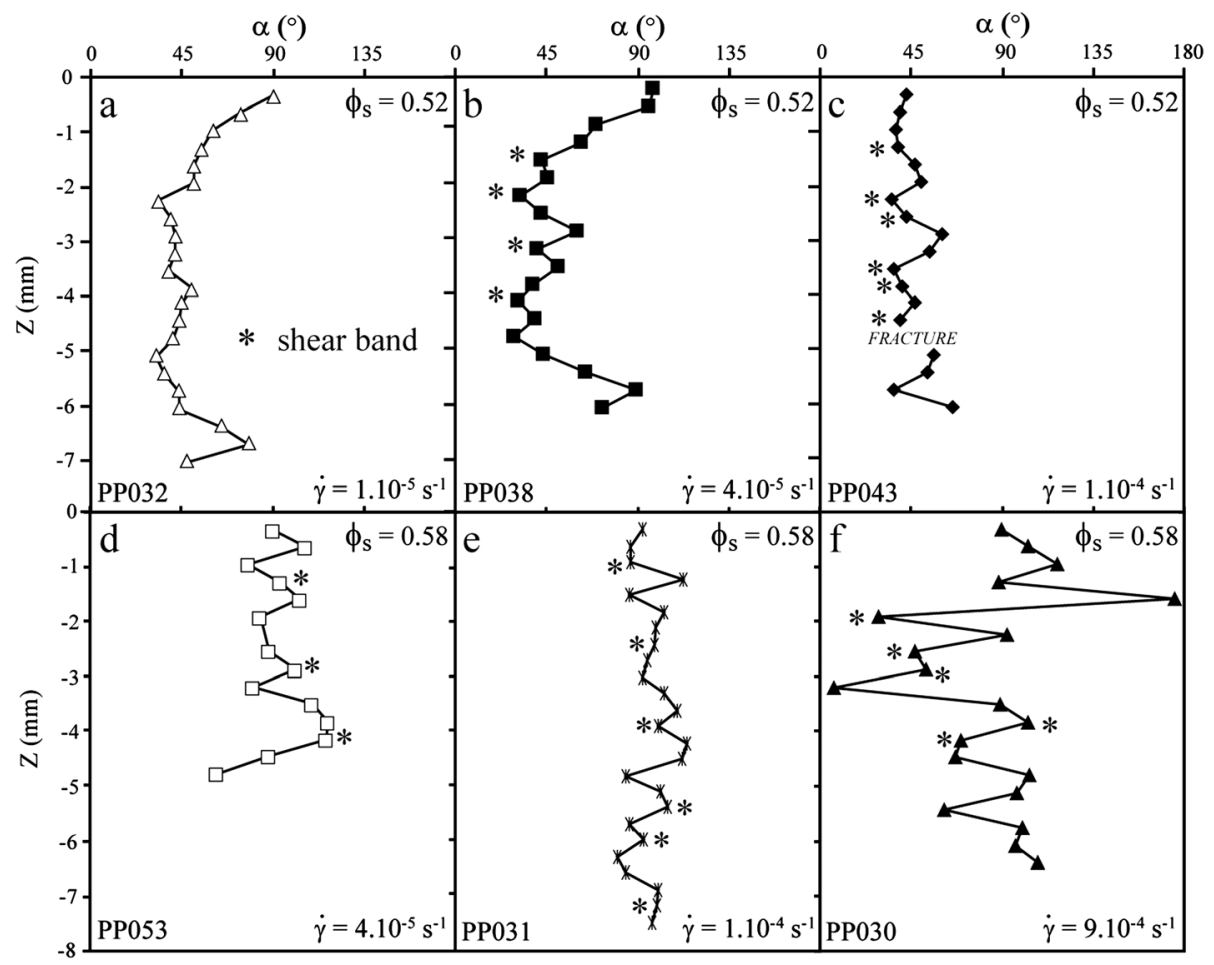

Figure 7. Distribution of the shear bands along the z-axis of the samples ([XZ] plan) for experiments at $\phi_{\mathrm{s}}=0.52(\mathrm{a}-\mathrm{c})$ and $0.58(\mathrm{~d}$ and $\mathrm{e})$ and at different strain rates.

the [XZ] plane are the long axis of the crystals. The stress increases until reaching a critical value that corresponds to the stress sufficient to break the crystal network. This value is associated to the maximum of the differential stress observed on the rheological curves. Once this value is exceeded, the crystal network breaks, generating a strong decrease of the strength of the sample, which corresponds to the strong weakening observed. Consequently, fragmentation bands develop, with a strongly reduced mean crystal size. The 3-D CPO that indicates that the grain size reduction observed in the shear zones is not due to recrystallization or to the reorientation of the long axes of plagioclases over the [XZ] plane but more likely originates from the stress propagation over the solid network resulting in the breakage of crystals in the highly deformed zones. Once these bands are formed, the system reaches a nearly steady-state behavior as shown by the few loss of the stress for the high shear strains. These suspensions can be considered as material with complex rheological behavior because they deform with a brittle behavior in the shear bands with evidence for intense fragmentation of the crystals [Caricchi et al., 2008; Cordonnier et al., 2009].

[34] For $\phi_{\mathrm{s}}>0.58$, a domain IV is established (Figure 8). At this crystal fraction, the size and the shape ratio of the crystals are reduced from $\mathrm{R}=4$ to 2.5 . Consequently, crystals can more easily accommodate the deformation by rotation and rigid translation. This leads to a nearly steadystate behavior of the differential stress at large strains with a stabilization of the apparent viscosity at $10^{11} \mathrm{~Pa} \mathrm{~s}$. This result is in agreement with previous studies that found the same rheological behavior for particles with a very low anisotropy [Arbaret et al., 2007; Caricchi et al., 2007; Champallier et al., 2008].

\subsection{Influence of the Shape of Crystals on the Rheological Behavior of Magmatic Suspensions}

[35] Our study experimentally demonstrates the existence of a rheological threshold/transition in plagioclase-bearing magmatic suspensions. Based on the Einstein-Roscoe equation for the low crystal fractions $\left(\phi_{\mathrm{s}}<0.2\right)$, a strong increase of the viscosity is evidenced for $\phi_{\mathrm{s}}$ close to $0.3 \pm 0.1$ (Figure 8). The rheological transition corresponds to a large viscosity change of the suspensions but also to an evolution from a Newtonian to a non-Newtonian behavior for our plagioclasebearing magmas.

[36] The shape ratio of the crystals should have an influence on the crystal fraction at which this transition occurs. However, due to the lack of experimental constraints, this control has remained debated [Lejeune and Richet, 1995; Saar et al., 2001; Petford, 2003; Mueller et al., 2010; Picard et al., 2011]. To express the influence of the shape ratio of the crystals on the mechanical behavior of the suspensions, we compare the relative viscosities obtained in this study with those obtained on suspensions composed of nearly isometric particles [Caricchi et al., 2007; Champallier et al., 2008] and anisometric particles [Sato, 2005; Ishibashi and Sato, 2007; Cordonnier et al., 2009] (Figure 8). We introduce the relative viscosity $\eta_{\mathrm{r}}$ defined as the ratio between the apparent viscosity $\eta_{\text {app }}$ (measured) and the viscosity of the interstitial melt $\eta_{0}$. The latter is calculated for each deformed suspension at the temperature of the deformation experiment [Giordano et al., 2008] using the major element composition of the interstitial melt determined by electron microprobe and the estimated melt $\mathrm{H}_{2} \mathrm{O}$ concentration. Therefore, $\eta_{\mathrm{r}}$ measures the influence of crystallinity factors (e.g., crystal fraction and shape) on the rheology. 


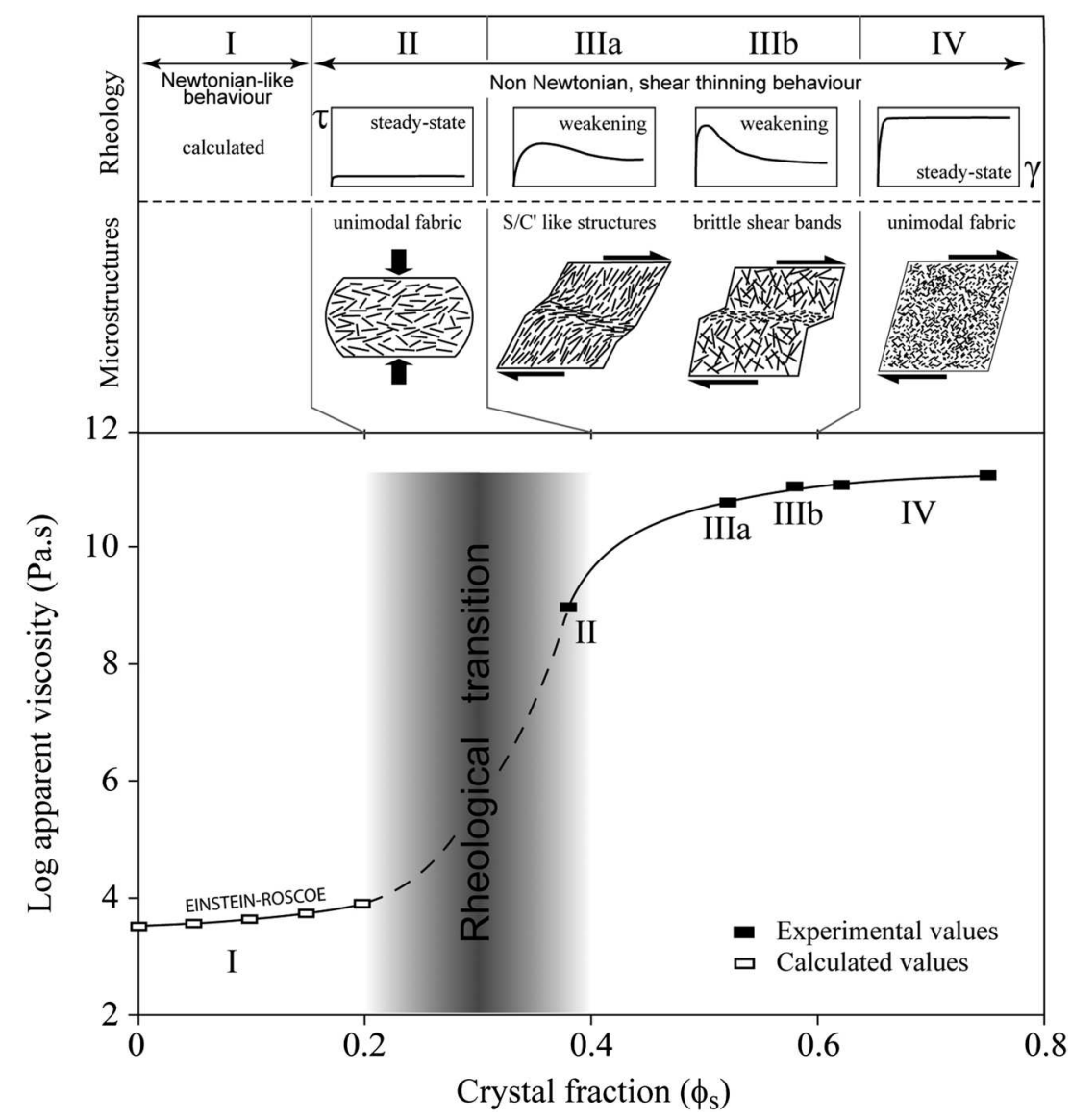

Figure 8. Apparent viscosity as a function of the crystal fraction. (black rectangles) Experimental data. (white rectangle) Viscosity for a pure melt calculated using the model of Giordano et al. [2008]. Viscosities up to $\phi_{\mathrm{s}}=0.2$ are calculated using the Einstein-Roscoe equation. Top sketches illustrate the interplay between the microstructures and the rheological behavior corresponding to the four domains (I-IV).

[37] For $\phi<0.2$, the relative viscosities are similar for all suspensions and can be fitted by the Einstein-Roscoe equation [Einstein, 1911; Roscoe, 1952] (Figure 9). For $\phi>0.2$, the relative viscosities calculated for our plagioclase suspensions greatly increase to reach a maximum difference of $\sim 5$ $\log$ units at $\phi \sim 0.5$ compared with suspensions containing quasi-isometric crystals. Moreover, the Einstein-Roscoe equation fits quite well the rheological data for the quasiisometric suspensions for $\phi<0.6$. In contrast, our data are underestimated by several orders of magnitude (Figure 8; $0.3<\phi<0.6$ ). Moreover, the results of Cordonnier et al. [2009] on plagioclase-bearing suspensions exhibit lower viscosities than those obtained in this study. In their experiments, Cordonnier et al. [2009] have generated breakage of the crystals, which implies a decrease of their mean shape ratio [Forien et al., 2011]. Therefore, the broken plagioclase may act as quasi-isometric particles, inducing a decrease of the relative viscosity of the suspension.

[38] Our study experimentally demonstrates that the shape of crystals is a critical parameter controlling the relative viscosities and the crystal fraction at which the rheological threshold occurs. Elongated particles are able to generate a crystal network and thus increase the viscosity of the suspension at lower crystal fractions than expected from the Einstein-Roscoe theory [Einstein, 1911; Roscoe, 1952].
The development of a continuous crystal network at low crystal fractions has been demonstrated numerically by Saar et al. [2001]. Comparison of data shows that, for anisometric particles, a rheological threshold characterized by the strong increase of the viscosity is reached at a critical crystal fraction $\phi_{\mathrm{c}} \sim 0.3$ [Sato, 2005; Ishibashi and Sato, 2007; this study], whereas it is reached at $\phi_{\mathrm{c}} \sim 0.5$ for nearly isometric particles [Caricchi et al., 2007; Champallier et al., 2008] (Figure 9). It is worth emphasizing that the determination of the precise onset of the rheological transition should consider the specific shape of the crystals and not only their volumic fraction through the Einstein-Roscoe equation. In addition, whatever the shape ratio, an increase of the strain rate from $1.0 \times 10^{-5}$ to $1.0 \times 10^{-3} \mathrm{~s}^{-1}$ implies a decrease of $\eta_{\mathrm{r}}$ of $\sim 2$ orders of magnitude (Figure 9). This is easily explained by the increase of either the number of shear bands at $\phi_{\mathrm{s}}=0.52$ or the thickness of the bands at $\phi_{\mathrm{s}}=$ 0.58 , with increasing the strain rate that contributes to weaken the samples and thus implies this decrease of the relative viscosity.

\subsection{Local Deformation Mechanisms}

[39] The study of microstructures obtained for $\phi_{\mathrm{s}}=0.52$ and 0.58 demonstrates that the applied stress is partially or totally accommodated by the development of shear bands. 


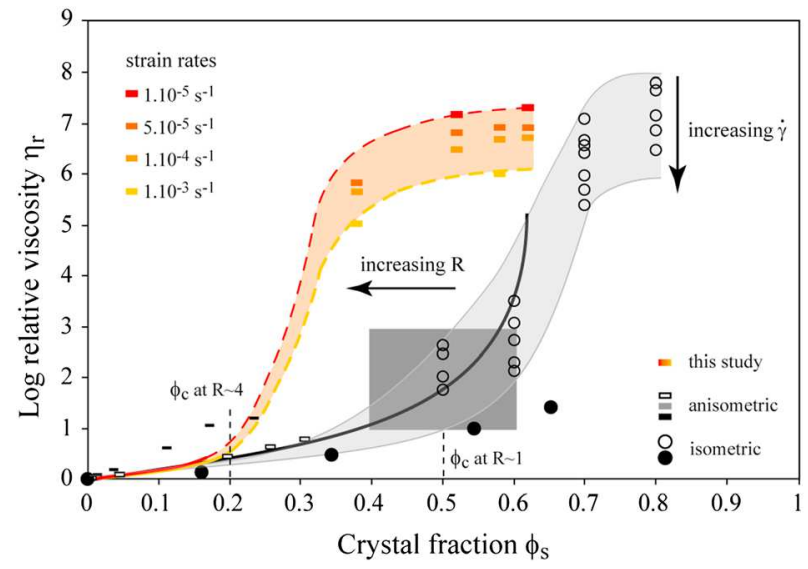

Figure 9. Relative viscosities as a function of the crystal fraction. Data for anisometric particles (rectangles) from this study (color symbols), Cordonnier et al. [2009] (dark gray area), Ishibashi and Sato [2007] (open symbols), and Sato [2005] (full symbols) are plotted. Data from nearly isometric particles (circles) from Caricchi et al. [2007] (open symbols and light gray area) and Champallier et al. [2008] (full symbols). Color coding relates experimental data from this study to applied strain rates. The errors are smaller than symbol sizes. The continuous black curve gives the relative viscosities calculated using the Einstein-Roscoe equation using $\eta_{0}=10^{4} \mathrm{~Pa} \mathrm{~s}$, an exponent (n) of 2.5 and $\phi_{\max }=0.62$.

Conversely, these discrete structures influence the rheological behavior of the suspensions. In particular, shear bands reduce the strength of the plagioclase-bearing suspension and induce strain weakening at large strains. The orientation of the crystals inside the shear bands is almost parallel to the bulk shear direction (Figure $6 \mathrm{~b} ; \phi_{\mathrm{s}}=0.52$ ). This indicates that the fabric inside the shear bands likely corresponds to transtensional shear zone geometry in which the extensional flow apophyse is always parallel to the bulk simple shear [Weijermars, 1998]. Similar structures have already been evidenced in natural magmatic rocks such as $\mathrm{S} / \mathrm{C}^{\prime}$-like structures (called trachytic textures; Smith, 2002), asymmetric textural domains [Závada et al., 2009], and local shear bands [Sen and Mamtani, 2006]. All are characterized by strong alignment of crystals and, in some cases, grain size reduction [Sen and Mamtani, 2006], as obtained in our experiments for $\phi_{\mathrm{s}}=0.58$. Experiments made on natural rocks have also shown discrete structures with flow banding of crystal fragmentation [Cordonnier et al., 2009] or fracturing of the samples [Caricchi et al., 2008].

[40] The number and spacing of shear bands are directly related to the applied bulk strain rates (Figure 7). Furthermore, increasing the strain rate by $1 \log$ unit leads to a decrease of the relative viscosity by $\sim 0.7 \pm 0.1 \log$ unit (Figure 9; Table 2). To quantify the local shear strains, strain rates, and viscosities within the shear bands, we assume in first approximation that all the observed shear bands are formed at the same time and react continuously during the deformation. For each crystal fraction, a strain partitioning model based on the observed structures is used as detailed below:
[41] 1. For $\phi_{\mathrm{s}}=0.52$, the plagioclase suspension deforms like a ductile material and the development of shear bands is influenced by the interaction of the rotating particles and thus by the strain rates [Smith, 1997]. Because the interactions increase with the strain rate, the number of shears bands increase too. We assume that a pervasive fabric oriented at $45^{\circ}$ from the shear direction is already acquired at $\gamma \approx 0.1$ following the Jeffery's model of rigid body rotation [Jeffery, 1922; Fernandez et al., 1983].

[42] 2. For $\phi_{\mathrm{s}}=0.58$, samples undergo brittle deformation. The applied stress is fully accommodated by the shear bands as the pervasive fabric is not deformed.

[43] For both solid fractions, we assume that once the bands are created, the applied stress is entirely accommodated in the existing bands rather than by creating new ones. Therefore, for both crystal fractions, we assume that the shear bands initiate at $\gamma \approx 0.1$ and accommodate all the subsequent applied stress. The local shear strain can be defined as

$$
\gamma_{l o c}=\frac{d \theta}{2 l_{\text {band }}} ;
$$

where $\theta$ is the angular displacement at a given shear strain $\gamma$, $d$ the diameter of the sample and $l_{\text {band }}$ the cumulative thickness of the shear bands. Then, we can calculate the local strain rates as:

$$
\dot{\gamma}_{l o c}=\frac{\gamma_{l o c}}{t} ;
$$

with $\gamma_{\text {loc }}$ is the local strain rate $\left(\mathrm{s}^{-1}\right)$ and $t(\mathrm{~s})$ the experimental time necessary to reach a given shear strain $\gamma$. Finally, the local viscosities in the shear bands $\eta_{\text {loc }}$ can be estimated using the measured stress $\tau$ as

$$
\eta_{l o c}=\frac{\tau}{\dot{\gamma}_{l o c}} ;
$$

with $\tau(\mathrm{Pa})$ the measured stress at a given shear strain $\gamma$.

[44] For both crystal fractions, we found local strains $\gamma_{\text {loc }}$ and strain rates $\dot{\gamma}_{l o c} \sim 30$ times higher than the bulk strains and strain rates (Table 3). The viscosities within the shear bands decrease by $\sim 1.5$ orders of magnitude compared with the apparent viscosities of the bulk, irrespective of the crystal fraction.

[45] At $\phi_{\mathrm{s}}=0.52$, this decrease in viscosity could be attributed to the SPO of plagioclases in the shear bands (Figure 6b, zone 2) as also suggested by Ishibashi and Sato [2007] on dilute plagioclase suspensions. Alignment of crystals in a sheared medium increases the ability of the fluid to flow by reducing its tortuosity and consequently the apparent viscosity of the plagioclase suspension [Petford, 2009].

[46] At $\phi_{\mathrm{s}}=0.58$, the shear bands are characterized by a strong grain size reduction and alignment of resulting fragments (Figure 6c, zone 4). Combination of these two properties could be the cause of a lower viscosity in the shear bands. Such an effect has been demonstrated on experimentally deformed Unzen andesites by Cordonnier et al. [2009].

\subsection{Applications on Natural Systems}

[47] Our experiments evidence the control that localization structures exert on the rheological behavior of crystal-rich magmas during ascent and emplacement. Numerous based 
PICARD ET AL.: RHEOLOGICAL TRANSITION IN MAGMAS

Table 3. Rheological Properties of the Shear Bands

\begin{tabular}{|c|c|c|c|c|c|c|c|c|}
\hline $\begin{array}{l}\text { Crystal } \\
\text { fraction }\end{array}$ & Run & $\gamma$ & $\gamma_{\text {loc }}$ & $\left(\mathrm{s}^{-1}\right)$ & $\begin{array}{l}\gamma \text { loc } \\
\left(\mathrm{s}^{-1}\right)\end{array}$ & $\begin{array}{c}\log \eta_{\text {app }} \\
(\text { Pa.s) }\end{array}$ & $\begin{array}{c}\log \eta_{\text {loc }} \\
(\mathrm{Pa} . \mathrm{s})\end{array}$ & $\underset{\eta_{\text {app }} / \eta_{\text {loc }}}{\Delta \eta}$ \\
\hline \multirow[t]{3}{*}{0.52} & PP038 & 0.5 & 13.94 & $4.1 \times 10^{-5}$ & $1.39 \times 10^{-3}$ & 10.83 & 9.25 & 1.72 \\
\hline & PP043 & 0.5 & 9.47 & $1.1 \times 10^{-4}$ & $2.36 \times 10^{-3}$ & 10.49 & 9.10 & 1.56 \\
\hline & & 1.4 & 30.51 & $1.1 \times 10^{-4}$ & $2.36 \times 10^{-3}$ & 10.24 & 8.93 & 1.58 \\
\hline \multirow[t]{3}{*}{0.58} & PP053 & 0.5 & 19.27 & $4.4 \times 10^{-5}$ & $2.29 \times 10^{-3}$ & 11.01 & 9.29 & 1.58 \\
\hline & PP031 & 0.5 & 14.40 & $9.1 \times 10^{-5}$ & $3.27 \times 10^{-3}$ & 10.78 & 9.22 & 1.39 \\
\hline & PP030 & 0.5 & 13.31 & $9.4 \times 10^{-4}$ & $2.84 \times 10^{-2}$ & 10.10 & 8.52 & 1.31 \\
\hline
\end{tabular}

field studies point out the transition from a magma flow stage, characterized by the pervasive alignment of anisotropic euhedral crystals, to a connected solid network in which localization structures may develop [Blumenfeld and Bouchez, 1988; Paterson et al., 1989; Bouchez et al., 1992; Petford, 2003; Vernon et al., 2004; Barbey, 2009].

[48] In plutons emplaced at the intermediate crustal level, the macroscopic localization structures characteristic of a continuous transition from magmatic to late, hypersolidus, magmatic deformation are rarely fully documented. The development of such structures will depend on a delicate balance between the regional strain, ascent, and crystallization rates [Paterson et al., 1989; Petford, 2003; Vernon et al., 2004]. Furthermore, mineral fabrics and discrete structures developed during the latest stage of cooling plutons can be easily erased by subsequent, even small, solid-state penetrative deformation [Rosenberg, 2001; Zibra et al., 2012]. Shear zones characterized by local reorientation of anisotropic euhedral crystals with little evidence of intracrystalline deformation or crystal fracturing (cataclase) as we reproduced for crystal fraction $\phi=0.52$ are rarely reported in granites. Field examples are often restricted to mushes zones formed by the accumulation of anisotropic crystals such as large euhedral K-feldspar megacrysts [Sen and Mamtani, 2006; Barbey, 2009]. The anisotropic shape of the K-feldspar megacrysts favor the formation of a solid network in which the shear zones initiate and propagate by crystal reorientation. This implies that the crystal network trapped a large amount of residual melt to allow the free rotation of the euhedral K-feldspar megacrysts without any stress accommodation by intracrystalline deformation or cataclase [Vernon and Paterson, 2008; Barbey, 2009]. Furthermore, this suggests that such shear zones develop early during the crystallization history and confirm the conclusion that K-feldpar megacrysts begin to crystallize at melt fraction of $\sim 0.6$ [Winkler and Schultes, 1982; Vernon and Paterson, 2008]. Finally, if strain localization enlarges, crystal mushes could be homogenized and remobilized, leading to volcanic eruptions [Burgisser and Bergantz; 2011].

[49] In the shallow region of volcanic conduits and during final emplacement of lava flows at the surface, the crystallization of feldspar microlites is promoted by cooling and decompression at slow ascent rates [Martel, 2012]. The formation of a solid network during ascent at relatively low crystal fraction drastically increases the viscosity of the magmas leading to the formation of a magma plug and the overpressurization of the underlying magma column [Picard et al., 2011]. With increasing crystal fraction, strain partitioning occurs in response to the high strength accumulated in the plug and forms a connected network composed of regularly spaced discrete shear bands characteristics of feldspar-rich lava (trachytic textures) [Smith, 2002]. At the highest crystal fractions, brittle shear bands characterized by an intense crystal fragmentation develop [Allen and McPhie, 2003; Forien et al., 2011; this study for $\phi=0.58]$. These structures are associated to strain weakening and shear thinning behavior and typify restricted zones of intense shear and fast local strain rates such as those near the conduit margins [Geshi, 2001] and at the base of lava flows [Smith, 1996; Polacci et al., 2005]. They would enhance the plug ascent inside the conduit and thus may facilitate the final emplacement at the surface of highly viscous, crystal rich bodies, as domes and spins [Sparks, 1997; Hale and Wadge, 2008; Závada et al., 2009; Pistone et al., 2012].

\section{Conclusions}

[50] We have performed deformation experiments on plagioclase-bearing melts $\left(0.38<\phi_{\mathrm{s}}<0.75\right), \mathrm{P}=300 \mathrm{MPa}$, $800<\mathrm{T}<900^{\circ} \mathrm{C}$, and strain rates from $1.0 \times 10^{-5}$ to 1.0 $\times 10^{-3} \mathrm{~s}^{-1}$. All suspensions show a non-Newtonian shear thinning behavior as similarly measured on suspensions containing isometric crystals [Caricchi et al., 2007; Champallier et al., 2008]. Four successive rheological domains are identified from the existing data and rheological models at low crystal fractions $\left(\phi_{\mathrm{s}}<0.3\right)$. In particular, a progressive evolution from a pervasive fabric characterized by steady-state flow to a strain partitioning fabric with a strain weakening behavior is found. The crystal fraction at which this rheological transition occurs in plagioclase-bearing magmas is $\phi_{\mathrm{c}} \sim 0.3$ but is $\phi_{\mathrm{c}} \sim 0.5$ for magmatic suspensions of isometric particles [Caricchi et al., 2007]. Across the rheological transition, the apparent viscosity of plagioclase-bearing magmas increases by $\sim 6$ orders of magnitude. For $\sim 0.3<\phi_{\mathrm{s}}<\sim 0.5$, plagioclase-bearing suspensions exhibit viscosities 5 orders of magnitude higher than suspensions of isometric particles. For $0.5<\phi_{\mathrm{s}}<0.6$ and $\gamma>0.5$, strain partitioning occurs with the development of discrete localized shear bands whose number and spacing are strain rate dependent.

[51] Acknowledgments. This study was funded by the French programs ACI Fabriques magmatiques (ACI JC3013) and ANR EXPLANT (ANR-05-CATT-003). The European Union Research Infrastructures: Transnational Access Programme (131) supported the EBSD analyses at Bayreuth. O. Rouer and A. Genty helped with the scanning electron microscopy and F. Heidelbach helped with the electron backscattered diffraction (EBSD) analyses. L. Peilleron provided useful technical assistance. The comments and reviews of three anonymous reviewers are appreciated.

\section{References}

Allen, S. R., and J. McPhie (2003), Phenocryst fragments in rhyolitic lavas and lava domes, J. Volcanol. Geotherm. Res., 126(3-4), 263-283. 


\section{PICARD ET AL.: RHEOLOGICAL TRANSITION IN MAGMAS}

Arbaret, L., H. Diot, and J. L. Bouchez (1996), Shape fabrics of particles in low concentration suspensions: 2D analogue experiments and application to tiling magma, J. Struct. Geol., 18, 941-950.

Arbaret, L., H. Diot, J. L. Bouchez, M. Saint Blanquat, and P. Lespinasse (1997), Analogue 3D simple-shear experiments of magmatic biotite subfabrics, in Granites: From segregation of melt to emplacement fabric, edited by J. L. Bouchez, D. H. W. Hutton, and W. E. Stephens, pp. 129-143, Kluwer Academic Publishers, Netherlands.

Arbaret, L., M. Bystricky, and R. Champallier (2007), Microstructures and rheology of hydrous synthetic magmatic suspensions deformed in torsion at high pressure, J. Geophys. Res., 112, B10208. doi:10.1029/ 2006JB004856.

Arzi, A. A. (1978), Critical phenomena in the rheology of partially melted rocks, Tectonophys., 44, 173-184.

Bagdassarov, N. S., and D. B. Dingwell (1992), A rheological investigation of vesicular rhyolite, J. Volcanol. Geotherm. Res., 50, 307-322.

Bagdassarov, N. S, and A. Dorfman (1998), Granite rheology: magma flow and melt migration, J. Geol. Soc., 155, 863-872.

Bagdassarov, N. S., and H. Pinkerton (2004), Transient phenomena in vesicual lava flows based on laboratory experiments with analogue materials, J. Volcanol. Geotherm. Res., 132, 115-136.

Bagdassarov, N. S., D. B. Dingwell, and S. L. Webb (1994), Viscoelasticity of crystal- and bubble-bearing rhyolite melts, Phys. Earth Planet. Inter., 83, 83-99.

Barbey, P. (2009), Layering and schlieren in granitoids: a record of interactions between magma emplacement, crystallization and deformation in growing plutons, Geol. Belg., 12(3/4), 109-133.

Blumenfeld, P., and J.L. Bouchez (1988), Shear criteria in granite and migmatite deformed in the magmatic and solid states, J. Struct. Geol. 4, 361-372.

Bottinga, Y., and P. Richet (1995), Silicate melts: The "anomalous" pressure dependence of the viscosity, Geochim. Cosmochim. Acta, 59, 2725-2731.

Bouchez, J.L., C. Delas, G. Gleizes, A. Nédélec and M. Cuney, (1992), Submagmatic microfractures in granites, Geology, 20, 35-38.

Burgisser, A., and G. W. Bergantz (2011), A rapid mechanism to remobilize and homogenize crystalline magma bodies, Nature, 471, 212-215, doi:10.1038/nature09799.

Caricchi, L., L. Burlini, P. Ulmer, T. Gerya, M. Vassalli, and P. Papale (2007), Non-Newtonian rheology of crystal-bearing magmas and implications for magma ascent dynamics, Earth Planet. Sci. Lett., 264, 402-419.

Caricchi, L., D. Giordano, L. Burlini, P. Ulmer, and C. Romano (2008), Rheological properties of magma from the 1538 eruption of Monte Nuovo (Phlegrean Fields, Italy): An experimental study, Chem. Geol., 256, 158-171.

Champallier, R., M. Bystricky, and L. Arbaret (2008), Experimental investigation of magma rheology at $300 \mathrm{MPa}$ : From pure hydrous melt to 75 vol. \% of crystals, Earth Planet. Sci. Lett., 267, 571-583.

Chong, J. S., E. B. Christiansen, and A. D. Baer (1971), Rheology of concentrated suspensions, J. Appl. Polym. Sci., 15, 2007-2021, doi:10.1002 app.1971.070150818.

Cordonnier, B., K.-H. Hess, Y. Lavallee, and D. B. Dingwell (2009), Rheological properties of dome lavas: Case study of Unzen volcano, Earth Planet. Sci. Lett., 279, 263-272.

Dingwell, D. B., C. Romano, and K. H. Hess (1996), The effect of water on the viscosity of a haplogranitic melt under P-T-X conditions relevant to silicic volcanism, Contrib. Mineral. Petrol., 124, 19-28.

Einstein, A. (1911), Berichtigung zu meiner Arbeit: Eine neue Bestimmung der Moleküldimensionen, Ann. Phys., 34, 591-592.

Fernandez, A. N., and D. Gasquet (1994), Relative rheological evolution of chemically contrasted coeval magmas: Example of the Tichka plutonic complex (Morocco), Contrib. Mineral. Petrol., 116, 316-326.

Fernandez, A., and J. Fernandez-Catuxo (1997), 3D biotite shape fabric experiments under simple shear, in Granites: From segregation of melt to emplacement fabric, edited by J. L. Bouchez, D.H.W. Hutton, and W.E. Stephens, pp. 145-158, Kluwer Academic Publishers, Netherlands.

Fernandez, A., J. L. Febesse, and J. F. Mezure (1983), Theoretical and experimental study of fabrics developed by different shaped markers in two-dimensional simple shear, Bull. Soc. Geol. Fr., 3, 319-326.

Forien, M., L. Arbaret, A. Burgisser, and R. Champallier (2011), Experimental constrains on shear-induced crystal breakage in magmas, J. Geophys. Res. 116, B08217, doi:10.1029/2010JB008026.

Frost, H. J., and M. F. Ashby (1982), Deformation-mechanism maps: The Plasticity and Creep of Metals and Ceramics, p. 167, Pergamon Press, New York.

Geshi, N. (2001), Melt segregation by localized shear deformation and fracturing during crystallization of magma in shallow intrusions of the Otoge volcanic complex, central Japan, J. Volcanol. Geotherm. Res., 106, 285-300.

Giordano, D., J. K. Russel, and D. B. Dingwell (2008), Viscosity of magmatic liquids: a model, Earth Planet. Sci. Lett., 271, 123-134.
Hale, A. J., and G. Wadge (2008), The transition from endogeneous to exogeneous growth of lava domes with the development of shear bands, J. Volcanol. Geotherm. Res., 171, 237-257, doi:10.1016/j.jvolgeores.2007.12.016.

Hawkes, I., and M. Mellor (1970), Uniaxial testing in rockmechanics laboratories, Eng. Geol., 4, 177-285.

Heidelbach, F., K. Kunze, and H. R. Wenk (2000), Texture analysis of a recrystallized quartzite using electron diffraction in the scanning electron microscope, J. Struct. Geol., 22, 91-104.

Hess, K.-U., and D. B. Dingwell (1996), Viscosities of hydrous leucogranitic melts; A non-Arrhenian model, Am. Mineral., 81, 1297-1300.

Hess, K.-U., D. B. Dingwell, and E. Rossler (1996), Parameterization of viscosity-temperature relations of aluminisilicate melts, Chem. Geol. $128,155-163$

Ildefonse, B., P. Launeau, J. L. Bouchez, and A. Fernandez (1992a), Effect of mechanical interactions on the development of shape preferred orientations: a two dimensional experimental approach, J. Struct. Geol., 14, 73-83.

Ildefonse, B., D. Sokoutis, and N. S. Mancktelow (1992b), Mechanical interactions between rigid particles in a deforming ductile matrix. Analogue experiments in simple shear flow, J. Struct. Geol., 14, 1253-1266.

Ishibashi, H. (2009), Non-Newtonian behaviour of plagioclase-bearing basaltic magma: Subliquidus viscosity measurement of the 1707 basalt of Fuji volcano, Japan, J. Volcanol. Geotherm. Res., 181, 78-88.

Ishibashi, H., and H. Sato (2007), Viscosity measurements of subliquidus magmas: Alkali olivine basalt from the Higashi-Matsuura district, Southwest Japan, J. Volcanol. Geotherm. Res., 160, 223-238.

Jeffery, G. B. (1922), The motion of ellipsoidal particles immersed in a viscous fluid, Proc. R. Soc., 102, 201-211.

Ježek, J. R., K. Melka, K. Schulmann, and Z. Venera (1994), The behaviour of rigid triaxial particles in viscous flows: Modelling of fabric evolution in a multiparticle system, Tectonophys., 229, 165-180.

Launeau, P., and P.Y.F. Robin (1996), Fabric analysis using the intercept method, Tectonophys., 267, 91-119.

Lejeune, A. M., and P. Richet (1995), Rheology of crystal-bearing silicate melts: An experimental study at high viscosities, J. Geophys. Res., 100, 4215-4229.

Lejeune, A. M., Y. Bottinga, T. W. Trull, and P. Richet (1999), Rheology of bubble-bearing magmas, Earth Planet. Sci. Lett., 166, 71-84.

Manga, M., J. Castro, K. Cashman, and M. Loewenberg (1998), Rheology of bubble-bearing magmas, J. Volcanol. Geotherm. Res., 87, 15-28.

Martel, C. (2012), Eruption Dynamics Inferred from Microlite Crystallization Experiments: Application to Plinian and Dome-forming Eruptions of Mt. Pelée (Martinique, Lesser Antilles), J. Petrol., 53(4), 699-725.

Mueller, S., E. W. Llewellin, and H. M. Mader (2010), The rheology of suspensions of solid particles, Proc. R. Soc., 466, 1201-1228.

Mysen, B.O. (1990), Relationships between silicate melt structure and petrologic processes, Earth Sci. Rev., 27, 281-365.

Papale, P., R. Moretti, and D. Barbato (2006), The compositional dependence of the saturation surface $\mathrm{H}_{2} \mathrm{O}+\mathrm{CO}_{2}$ fluids in silicate melts, Chem. Geol., 229, 78-95.

Paterson, S. R., Vernon, R. H. and Tobisch, O. T., (1989), A review of criteria for the identification of magmatic and tectonic foliation in granitoids, J. Struct. Geol., 11, 349-363.

Paterson, M., and D. Olgaard (2000), Rock deformation tests to large shear strains in torsion, J. Struct. Geol., 22, 1341-1358.

Petford, N. (2003), Rheology of granitic magmas during ascent and emplacement, Ann. Rev. Earth Planet. Sci., 31, 399-427.

Petford, N. (2009). Which effective viscosity?, Mineral. Mag., 73, 167-191.

Picard, D. (2009), Déformation HP-HT des magmas siliceux: contraintes expérimentales sur l'évolution structurale et les transitions rhéologiques aux moyennes et fortes cristallinités, Ph.D. thesis, Inst. Sci. Ter., ISTO, Orléans.

Picard, D., L. Arbaret, M. Pichavant, R. Champallier, and P. Launeau (2011), Rheology and microstructure of experimentally deformed plagioclase suspensions, Geology, 39, 747-750.

Pichavant, M. (1987), Effects of $\mathrm{B}$ and $\mathrm{H}_{2} \mathrm{O}$ on liquidus phase relations in the haplogranite system at $1 \mathrm{kbar}$, Am. Mineral., 72, 1056-1070.

Pistone, M., L. Caricchi, P. Ulmer, L. Burlini, P. Ardia, E. Reusser, F. Marone and L. Arbaret (2012), Deformation experiments of bubble-and crystalbearing magmas : Rheological and microstructural analysis, J. Geophys. Res., 117, B05208, doi:10.1029/2011JB008986.

Pinkerton, H., and R. J. Stevenson (1992), Methods of determining the rheological properties of magma at sub-liquidus temperatures, J. Volcanol. Geotherm. Res., 53, 47-66.

Polacci, M., M. Rosi, P. Landi, A. Di Muro, and P. Papale (2005), Novel interpretation for shift between eruptive styles in some volcanoes, Eos Trans. Amer. Geophys. Union, 87, 335-336.

Richet, P., A. M. Lejeune, F. Holtz, and J. Roux (1996), Water and the viscosity of andesite melts, Chem. Geol., 128, 185-197.

Richet, P. G. Hovis, and A. Whittington (2006), Water and magmas: Thermal effects of exsolution, Earth Planet. Sci. Lett., 241, 972-977.

Roscoe, R. (1952), The viscosity of suspensions of rigid spheres, Br. J. Appl. Phys., 3, 267-269. 


\section{PICARD ET AL.: RHEOLOGICAL TRANSITION IN MAGMAS}

Rosenberg, C. L. (2001), Deformation of partially molten granite: a review and comparison of experimental and natural case studies, Int. J. Earth Sci., 90(1), 60-76.

Rosenberg, C. L., and R. Handy (2005), Experimental deformation of partially melted granite revisited: Implication for the continental crust, J. Metamorph. Geol., 23, 19-28.

Ryerson, F. J., H. C. Weed, and A. J. Piwinskii (1988), Rheology of subliquidus magmas, I. Picritic compositions, J. Geophys. Res., 93, 3421-3436.

Saar, M. O., M. Manga, K. V. Cashman, and S. Fremouw (2001), Numerical models of the onset of yield strength in crystal-melt suspensions, Earth Planet. Sci. Lett., 187, 367-379.

Sato, H. (2005), Viscosity measurement of subliquidus magmas: 1707 basalt of Fuji Volcano, J. Mineral. Petrol. Sci., 100, 133-142.

Sen, K., and M. A. Mamtani (2006), Magnetic fabric, shape preferred orientation and regional strain in granitic rocks, J. Struct Geol., 28, 1870-1882.

Shaw, H. R. (1969), Rheology of basalt in the melting range, J. Petrol., $10,510-535$.

Smith, J. V. (1996), Ductile-brittle transition structures in the basal shear zone of a rhyolite lava flow, eastern Australia, J. Volcanol. Geotherm. Res., 72, 217-223.

Smith, J. V. (1997), Shear thickening dilatancy in crystal-rich flows, J. Volcanol. Geotherm. Res., 79, 1-8.

Smith, J. V. (2002), Structural analysis of flow-related textures in lavas, Earth Sci. Rev., 57, 279-297.

Sparks, R. S. J. (1997), Causes and consequences of pressurization in lava dome eruptions, Earth Planet. Sci. Lett., 150, 177-189, doi:10.1016/ S0012-821X(97)00109-X
Stein, D. J., and F. J. Spera (1992), Rheology and microstructure of magmatic emulsions: theory and experiments, J. Volcanol. Geotherm. Res., 49, 157-174.

Van der Molen, I., and M. S. Pateron (1979), Experimental deformation of partially-melted granite, Contrib. Mineral. Petrol., 70, 299-318.

Vernon, R. H. and S. R. Paterson (2008), How late are K-feldpar megacrysts in granites. Lithos 104, 327-336.

Vernon, R. H., S. E. Johnson, and E. A. Melis (2004), Emplacement-related microstructures in the margin of a deformed pluton: the San José tonalite, Baja California, México, J. Struct Geol., 26, 1867-1884.

Vigneresse, J. L., P. Barbey, and M. Cuney (1996), Rheological transitions during partial melting and crystallisation with application to felsic magma segregation and transfer, J. Petrol., 37, 1579-1600.

Vigneresse, J. L., and B. Tikoff (1999), Strain partitioning during partial melting and crystallizing felsic magmas, Tectonophys., 312, 117-132.

Weijermars, R. (1998), Taylor-mill analogues for patterns of flow and deformation in rocks, J. Struct. Geol., 20, 77-92.

Winkler, H. G. F. and H. Schultes (1982), On the problem of alkali feldspar phenocrysts in granitic rocks, Neues Jb. Miner. Monat., 12, 558-564.

Závada, P., K. Schulmann, O. Lexa, F. Hrouda, J. Haloda, and P. Týcova (2009), The mechanism of flow and fabric development in mechanically anisotropic trachyte lava, J. Struct. Geol., 31, 1295-1307.

Zibra, I., J. H. Kruhl, A. Montanini, and R. Tribuzio (2012), Shearing of magma along a high-grade shear zone: evolution of microstructures during the transition from magmatic to solid-state flow, J. Struct. Geol. $37,150-160$. 